\title{
Recent Advances in the Kinetics of Oxygen Reduction
}

\author{
Radoslav Adžić \\ Department of Applied Sciences, Chemical Sciences Division \\ Brookhaven National Laboratory, Upton, NY 11973
}

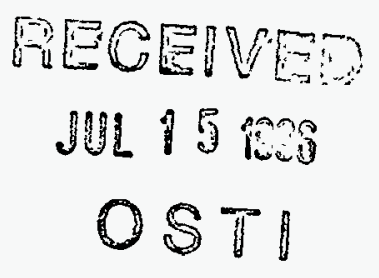

\section{Introduction}

Oxygen reduction is considered to be one of the most important electrocatalytic reactions because of its role in electrochemical energy conversion, several industrial processes and corrosion. Consequently, it was in the focus of electrochemical interest for many years. It continues to be a challenge for electrochemists because of its complex kinetics and the need for better electrocatalysts. The most notable need remains the improvement of the catalytic activity of the existing, and development of new, better, non-noble metal electrocatalysts. Despite a lack of a detailed mechanistic understanding of the reaction on many surfaces, considerable insights as to the course of the reaction have been acquired over the several decades of intensive investigation of this reaction.

Recent work on oxygen reduction has partly focused on the surface physics of oxygen electrocatalysts, aimed at an improved understanding of the structure and composition of the electrode surface in relation to its activity for this reaction. The molecular mechanisms derived from kinetic studies have been in some cases complemented by in situ spectroscopic data on the surface structure and chemical state of electrocatalysts. To a certain extent, this research was facilitated by a progress in the in situ applications of several structure-sensitive and spectroscopic techniques, use of synchrotron radiation techniques and by a preparation of well-ordered, clean, 
single-crystal rotating disk and ring-disk electrodes.

Further understanding of this reaction requires techniques for identification of the reaction intermediates and determination of their coverage. Complexes of transition metals with macrocyclic ligands continue to attract interest as electrocatalysts and understanding the origin of their catalytic activity remains a goal of on-going research.

There are several recent reviews of the work on oxygen reduction $(1,2,3,4,5)$. In this text, a review of the new advances in the understanding of the reaction kinetics and improvements of the electrocatalytic properties of some surfaces will be given with the focus on the recent ștudies of the relation of the surface properties to its activity and reaction kinetics.

\section{Background}

Despite intensive effort in studying fundamental problems of this reaction many aspects of its kinetics are not understood. Oxygen reduction is a multielectron reaction which usually includes several elementary steps in reaction mechanisms. In aqueous solutions, oxygen reduction appears to occur by two over-all pathways: a "direct" four-electron reduction and a "peroxide" pathway which involves $\mathrm{H}_{2} \mathrm{O}_{2}$ as the intermediate (6).

Direct four-electron pathway (acid and alkaline solutions)

$$
\begin{array}{ll}
\mathrm{O}_{2}+4 \mathrm{H}^{+}+4 \mathrm{e}^{-} \rightarrow 2 \mathrm{H}_{2} \mathrm{O} & \mathrm{E}_{0}=1.229 \mathrm{~V} \text { vs. NHE } \\
\mathrm{O}_{2}+2 \mathrm{H}_{2} \mathrm{O}+2 \mathrm{e}^{-} \rightarrow 4 \mathrm{OH}^{-} & \mathrm{E}_{0}=0.401 \mathrm{~V}
\end{array}
$$

Peroxide pathway

$\mathrm{O}_{2}+2 \mathrm{H}^{+}+2 \mathrm{e}^{-} \rightarrow \mathrm{H}_{2} \mathrm{O}_{2}$

$$
\mathrm{E}_{0}=0.67 \mathrm{~V}
$$

Peroxide can undergo further reduction or decomposition in acid solutions, 


\section{DISCLAIMER}

This report was prepared as an account of work sponsored by an agency of the United States Government. Neither the United States Government nor any agency thereof, nor any of their employees, makes any warranty, express or implied, or assumes any legal liability or responsibility for the accuracy, completeness, or usefulness of any information, apparatus, product, or process disclosed, or represents that its use would not infringe privately owned rights. Reference herein to any specific commercial product, process, or service by trade name, trademark, manufacturer, or otherwise does not necessarily constitute or imply its endorsement, recommendation, or favoring by the United States Government or any agency thereof. The views and opinions of authors expressed herein do not necessarily state or reflect those of the United States Government or any agency thereof. 


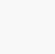


$\mathrm{H}_{2} \mathrm{O}_{2}+2 \mathrm{H}^{+}+2 \mathrm{e}^{\circ} \rightarrow 2 \mathrm{H}_{2} \mathrm{O} \quad \mathrm{E}_{0}=1.77 \mathrm{~V}$

$2 \mathrm{H}_{2} \mathrm{O}_{2} \rightarrow 2 \mathrm{H}_{2} \mathrm{O}+\mathrm{O}_{2}$

In alkaline solutions the reaction,

$\mathrm{O}_{2}+\mathrm{H}_{2} \mathrm{O}+2 \mathrm{e}^{-} \rightarrow \mathrm{HO}_{2}^{-}+\mathrm{OH}^{-} \quad \mathrm{E}_{0}=-0.065 \mathrm{~V}$

is followed by either, further two-electron reduction, or by decomposition,

$\mathrm{HO}_{2}^{-}+\mathrm{H}_{2} \mathrm{O}+2 \mathrm{e}^{-} \rightarrow 3 \mathrm{OH}^{-} \quad \mathrm{E}_{0}=0.867 \mathrm{~V}$

$2 \mathrm{HO}_{2}^{-} \rightarrow 2 \mathrm{H}^{\circ}+\mathrm{O}_{2}$

The principal tool for quantitative determination of the extent of these reactions is the rotating ring-disk technique (7). Peroxide is final reduction product on some less active surfaces which support a two-electron reduction. On some surfaces, the two pathways can occur in parallel. When peroxide is not desorbed from the surface before its further reduction, it cannot be detected at the ring electrode and a direct four-electron pathway and a four-electron series pathway are indistinguishable by the existing techniques. Besides peroxide, the superoxide radical $\mathrm{O}_{2}^{-}$can occur as a solution phase species in some cases.

The stability of the $\mathrm{O}-\mathrm{O}$ bond is considerable; the dissociation energy is $494 \mathrm{~kJ} / \mathrm{mol}$ which is the reason that the four-electron reduction is observed only on several metals. The dissociation energy of the $\mathrm{H}_{2} \mathrm{O}_{2}$ molecule is $146 \mathrm{~kJ} / \mathrm{mol}$ which explains its facile reduction on many surfaces.

The predicted and observed ground state of molecular oxygen is a triplet state $\left({ }^{3} \Sigma\right)$ with the $\mathrm{O}-\mathrm{O}$ bond formed by a $\pi$ bond between the $2 \mathrm{p}$ atomic orbitals which consist of a twoelectron $\sigma\left(3 \sigma_{g}\right)^{2}$ bond and a three-electron $\pi\left(1 \pi_{b}\right)^{2}\left(\pi_{g}\right)^{1}$ bond (8). A pair of bonding and antibonding orbitals is formed in these interactions. In $\mathrm{O}_{2}$ reduction, the electron is transferred 
to anti-bonding orbitals which increases the $\mathrm{O}-\mathrm{O}$ distance causing the vibrational frequency to decrease. The excess of bonding over non-bonding electrons is four which explains a high stability for the $\mathrm{O}_{2}$ molecule (9).

There is no reliable information on the sites and configuration for $\mathrm{O}_{2}$ adsorbed on an electrode surface. Yeager considered three plausible models for $\mathrm{O}_{2}$ adsorbed on metal surfaces given in Fig. 1:

i) $\mathrm{O}_{2}$ interacting with two bonds with a single substrate atom (Griffiths model), with a bond formed mainly between $\pi$-orbitals of $\mathrm{O}_{2}$ and empty $d_{2} 2$ orbitals on the metal surface atom with a $\pi$ back bond from the partially filled $d_{x y}$ or $d_{y z}$ orbitals of the metal to the antibonding $\pi^{*}$ orbitals of $\mathrm{O}_{2}(10)$.

ii) End-on adsorption through a single bond (Pauling model), in a $\sigma$ type bond in which $\sigma$ orbital of $\mathrm{O}_{2}$ donates electron density to an acceptor $d_{2} 2$ orbital on the metal.

iii) Bridge model, with two bonds with two sites, was proposed by Yeager (6), principally for the reaction on Pt-metals.

Dual adsorption sites are likely to be involved in the dissociation of $\mathrm{O}_{2}$, while single adsorption sites are probably sufficient for formation of hydrogen peroxide.

Thermodynamics of the oxygen reaction reduction has been clearly presented in reference (1). Still, particularly intriguing are the reasons for great difficulties in achieving the thermodynamic reversible potential $\mathrm{E}^{0}$ of $1.299 \mathrm{~V}$ for a four-electron reduiction which is a very irreversible reaction. The exchange current densities for the reactions (1) and (2) are about $10^{-11}$. $10^{-10} \mathrm{~A} / \mathrm{cm}^{2}$. Neither the mixed potential theory, nor the peroxide theory, explain satisfactorily why the open circuit potential is often around 1V. Dissolution of Pt was proposed recently as the 
anodic reaction for the mixed potential formation (11). A surprisingly high dissolution rate of $\mathrm{Pt}$ was quoted. A limiting current density of $5 \times 10^{-7} \mathrm{~A} / \mathrm{cm}^{2}$ at potentials above $0.75 \mathrm{~V}$ should be verified by additional techniques.

Actual formulation of the reaction involved with the slow charge transfer and the steps that follow, i.e. determination of reaction mechanism for various surfaces and the studies of the structural sensitivity of this reaction has been the focal point of research in this area in addition to the search for new catalytic materials.

\section{Gas Phase Studies of Oxygen Chemisorption}

Oxygen adsorption on clean metal surfaces in the gas phase has been the subject of numerous studies in order to establish the nature of the chemisorption, the bond strength, and the structure of the absorbed layer. Oxygen adsorbs in molecular form at low temperatures. Dissociative adsorption on platinum group metals occurs at temperatures in the range $150-300 \mathrm{~K}$. This is inferred from isotopic exchange experiments and from the lack of features characteristic of the $\mathrm{O}_{2}$ molecule in the ultraviolet photoemission spectroscopy (UPS) spectra and electron energy loss (EELS) spectra. The system oxygen-Pt(111) was investigated with a particularly broad variety of methods. The electronic structure of a chemisorbed oxygen molecule is strongly perturbed due to the hybridization with the metal substrate. This can be described as a charge transfer from the metal to the molecular $1 \pi_{\mathrm{g}}$ orbital. Peroxo $\left(\mathrm{O}_{2}{ }^{2 \cdot}\right)$ species was inferred from electron energy loss spectroscopy (EELS) (12). The near edge X-ray absorption spectroscopy (NEXAFS) measurements revealed the superoxo species $\left(\mathrm{O}_{2}^{\circ}\right)$, adsorbed on $\mathrm{Pt}(111)$ at $100 \mathrm{~K}(13)$. A bridge-bonded species with an 0-O stretching frequency of $v=700 \mathrm{~cm}^{-1}$ and an on-top species with $v=875 \mathrm{~cm}^{-1}$, both of peroxo type, were inferred from EELS. All these studies agree that 
the dissociation is a thermally activated process on $\mathrm{Pt}(111)$ and that it occurs at temperatures above $150 \mathrm{~K}$ through a molecular precursor. The atomic adlayer is ordered and has a $(2 \times 2)$ structure. It has a frequency loss at $480 \mathrm{~cm}^{-1}$ attributed to a perpendicular Pt-O vibration of oxygen atoms adsorbed at the threefold hollow sites (12). A compilation of observed LEED patterns has been given by Engel and Ertl (14). A recent study with X-ray photelectron spectroscopy (XPS) identified three types of oxygen adsorbates on $\mathrm{Pt}(111)$, viz., physisorbed $\mathrm{O}_{2}$, at about $25 \mathrm{~K}$, chemisorbed, at $90-135 \mathrm{~K}$, and an atomic phase above $150 \mathrm{~K}$ (15). Although adsorption of $\mathrm{O}_{2}$ on bare and a water covered $\mathrm{Pt}$ surface can differ substantially, these data can be considered as strong support for reactions schemes for $\mathrm{Pt}$ which involve a dissociation of the $\mathrm{O}_{2}$ molecule in the first step.

Adsorption on $\mathrm{Pt}(110)$ produces oxygen in atomic form with two Pt-O vibrations at $300 \mathrm{~K}$ (16). The rate of dissociative $\mathrm{O}_{2}$ adsorption on $\mathrm{Pt}(110)$ was found generally faster than on $\mathrm{Pt}(111), \mathrm{Pt}(100)$ and reconstructed $\mathrm{Pt}(110)-(1 \times 2)$ surfaces. The reconstruction of $\mathrm{Pt}(100)$ makes the studies of $\mathrm{O}_{2}$ adsorption on this surface more complex and the agreement between various groups is not very good. The sticking probability of oxygen on the unreconstructed $\mathrm{Pt}(100)-(1 \times 1)$ is higher than on the hex-reconstructed $\mathrm{Pt}(100)$ (17). For $\mathrm{Pt}(100), \mathrm{Pt}(210)$ and $\mathrm{Pt}(321)$, the lowand high-coverage states of oxygen have been found (18). The low-coverage state seems to be atomic oxygen, while the nature of the high-coverage state is unclear at present.

The interaction of silver with $\mathrm{O}_{2}$ has been the subject of considerable attention over the recent years. Physisorption, molecular chemisorption, dissociative adsorption and subsurface oxygen states were observed (19). Nonactivated dissociative adsorption has been observed for a $\mathrm{Ag}$ single crystal at $300 \mathrm{~K},(20)$ and also atomic oxygen and stable dioxygen molecules have been 
found on clean $\operatorname{Ag}(111)(19,21)$. Gold, as one of the.least active adsorbents does not chemisorb $\mathrm{O}_{2}$ at room temperature (22).

This short overview of the gas phase data on oxygen adsorption, when compared with a general picture of the behavior at the metal electrolyte solution interface, shows that the gas phase data could be relevant for $\mathrm{O}_{2}$ reduction on electrode surfaces.

\section{Methodologies}

Several important developments in methodologies for studying the oxygen reduction reaction have occurred during the last few years. Considerable new information was gathered by using well prepared single crystal rotating disk and disk-ring electrodes. Measurements with single crystal rotating gold $(23,24)$ and rotating ring-disk gold electrodes $(25)$ demonstrated pronounced and interesting structural sensitivity of $\mathrm{O}_{2}$ reduction. Moreover, they showed that the $\mathrm{Au}(100)$ surface provides the most active electrocatalyst in alkaline solutions (23). Comparatively smaller structural effects were shown of $\mathrm{O}_{2}$ reduction on silver single crystal electrodes (26). Most recently, single crystal rotating platinum disk (27) and ring-disk electrodes (28) were successfully used in studying this reaction. Besides demonstrating the effects of the structure of electrode surfaces on the kinetics of $\mathrm{O}_{2}$ reduction, these studies opened up new possibilities for studies of the effects of $\mathrm{OH}$ chemisorption, and anions and other adsorbates adsorption (see section 6). Hanging meniscus rotating disk electrode (HMRD) proposed by Cahan and Villulas (29) was also utilized in these studies. Although it does not follow exactly the Levich equation, it can be used for specific systems such as $\mathrm{O}_{2}$ reduction on $\mathrm{Pt}$ (27). The intensive $\mathrm{O}_{2}$ transport through the thin electrolyte film at the edge of the rotating disk may complicate measurements 
for gaseous reactants.

The extensive use of a rotating disk electrode (30) for reaction order determination in $\mathrm{O}_{2}$ reduction studies was reexamined by Vesovic et al. (31). The authors point out that the calculation of the reaction order, $m$, from the Levich-Koutecky equation, which is widely used for its determination, is bound to be inaccurate because of its insensitivity to the value of $\mathrm{m}$. Also, it has been shown for complex reaction mechanisms that none of the prescribed methods of obtaining the overall reaction order will give a proper answer unless the number of electrons exchanged is known a priori. For such reactions, the number of electrons exchanged is a function of the electrode potential and cannot be evaluated in a simple manner. The coupling of the number of electrons exchanged and the overall reaction order is inherent in the rotating disk experiment which limits its use in elucidating the overall kinetic parameters of the process. Wroblowa and Qaderi (32) agreed with restrictions of the use of the Levich-Koutecky equation for branching reactions since the disk current is more complex function of the angular velocity than that given by the equation, but pointed out its adequacy for simple redox reactions. Anastasijevic et al. (33) have demonstrated that the linearity of the $I_{D} / I_{R} ., v s . \omega^{-1 / 2}$ plot provides a reliable criterion for the first order reaction with respect to $\mathrm{O}_{2}$ (vide infra).

The chronic problem in studies of $\mathrm{O}_{2}$ reduction is the determination of the nature and coverage of adsorbed reaction intermediates. There is no simple adequate spectroscopic method for identification of adsorbed intermediates. A method for determining the coverage of adsorbed intermediates was proposed by $\mathrm{Wu}$ et al. (34). The rotating disk technique and potential step coulometry were used to monitor the diffusion controlled oxidation of the intermediates in oxygen reduction to determine the coverage of adsorbed and soluble intermediates near the electrode. The 
charge used to oxidize the soluble intermediate is

$Q_{1}=\left[1.61 n F A D^{1 / 3} v^{1 / 6} c_{8}^{*} \int_{0}^{\infty}(\vartheta C / \vartheta \varepsilon)_{\sigma-0} \mathrm{~d} \tau\right] \omega^{-1 / 2}$

where $A$ is the area, $\vartheta$ is the dynamic viscosity, $D$ is the diffusion coefficient of the soluble intermediate, $c_{s}{ }^{*}$ is the steady state surface concentration of the soluble intermediate before the potential switching, and $C=c_{\varepsilon} / c_{s}^{*} ; \varepsilon=Z / \delta$ and $\tau=D t / \delta^{2}$ are the dimensionless concentration of the soluble intermediate, dimensionless distance and dimensionless time respectively, while $\delta$ is the thickness of the diffusion layer. From the plot $\left(Q-Q_{b}\right)$ vs. $\omega^{-1 / 2}$, where $Q$ is the charge associated with the oxidation of $\mathrm{HO}_{2}^{-}$obtained as a function of $\omega^{-1 / 2}$, (corrected for $Q_{b}$, the rotation-independent charge in the absence of $\mathrm{O}_{2}$ reduction) the charge of adsorbed intermediate is obtained from the intercept with the $\left(Q-Q_{b}\right)$ axes. The surface concentration of the soluble intermediate is obtained from the slopes. This method can be useful for $\mathrm{O}_{2}$ reduction studies although it is not species-specific and gives a total amount of intermediates at that particular potential. The soluble intermediate is in most cases $\mathrm{H}_{2} \mathrm{O}_{2}$, but adsorbed intermediate cannot be distinguished. Fig. 2 shows the charge of adsorbed intermediate as a function of potential for $\mathrm{O}_{2}$ reduction on $\mathrm{Au}$ in $\mathrm{KOH}$ solution. The maximum coverage is seen at potential where on $\mathrm{Au}$, independent of the surface orientation, a quantitative peroxide generation takes place. An assumption of constant double layer capacity is involved in deriving eq. 9.

Micro electrodes have been used recently in studies of $\mathrm{O}_{2}$ reduction $(35,36)$. For $\mathrm{Pt}$, the apparent number of electrons exchanged in reduction of $\mathrm{O}_{2}$ molecule, $n_{\text {app }}$, was found to vary with mass-transfer coefficient while hydrogen peroxide was a major product under the conditions 
leading to a high mass-transfer coefficient (36). This was explained by fast removal of $\mathrm{H}_{2} \mathrm{O}_{2}$ from the surface under high mass-transfer coefficient before its further reduction. The results are corroborated by similar observation with $\mathrm{RDE}$ by the same authors. This would mean that the $\mathrm{O}_{2}$ reduction on Pt proceeds predominantly through the four-electron series mechanism which is one of the major open question of this reaction. The rotation rate dependence of the $n$ is not observed by other workers using the rotating disk electrodes at similar rotation rates. The measurements with micro electrodes are subject to various problems such as impurities and the leakage currents. This approach needs further examination.

Recent in situ applications of surface sensitive techniques to the electrochemical systems, involved also their application to the problems of $\mathrm{O}_{2}$ reduction. These techniques include, atomic force microscopy (AFM) (37), scanning tunneling microscopy (STM) (38), techniques with synchrotron radiation viz., surface x-ray scattering (SXS) (39), and x-ray absorption fine structure (EXAFS) $(40,41)$. New information can be obtained on surface structure (STM, AFM, SXS), chemical properties, such as bond lengths, coordination numbers and orbital vacancies (EXAFS) during the course of $\mathrm{O}_{2}$ reduction. Some of the results will be discussed in the subsequent sections.

On a practical side, it is worth mentioning again the problems caused by contamination of surfaces, other than $\mathbf{P t}$, by $\mathbf{P t}$ ring electrodes. This was often emphasized by Yeager (1). Wroblowa and Qaderi (32) pointed out on the possible decomposition of $\mathrm{HO}_{2}^{-}$on a $\mathrm{Pt}$ ring electrode which can affect the analysis of the disk-ring data. 


\section{Reaction Pathways and Mechanisms}

Reaction pathways, rather than reaction mechanisms, were often analyzed since in many cases, particularly for a four-electron $\mathrm{O}_{2}$ reduction, formulation of the latter proved too complex. These analyses are based on the data obtained by a rotating disk-ring technique which enables the quantitative determination of some of the reaction intermediates. Since the first proposition by Damjanovic et al. (42), there were several reaction schemes proposed for analyzing the diskring data and calculating the rates of various reaction steps $(43,44,45)$. The merits of various schemes were considered by Hsueh et al. (46) and Tarasevich et al. (1). The formulation of the species entering these schemes was partly based on the results of isotopic experiments. One of the difficulties in determining the correct scheme is that the number of experimentally obtained quantities from the ring-disk measurements is usually not sufficient to determine all the parameters of the model. Consequently, simple schemes were considered by several authors. Wroblowa et al.'s (47) scheme, which has two rate constants less than Bagotskii et al.'s scheme (48), is used most often for analysis of experimental ring-disk data. Oversimplification in some schemes has had undesirable effects. For instance, the failure to consider the adsorption / desorption equilibrium of hydrogen peroxide (42) led to insufficient diagnostic criteria regarding the series and direct paths for $\mathrm{O}_{2}$ reduction (44). Anastasijevic et al. (33) recently proposed a general scheme for analysis of the ring-disk measurements which includes nearly all the possible intermediates discussed in the literature. As in some previous schemes, the number of variables exceeds the number of measured parameters and many rate constants cannot be determined. The criteria that follow from the scheme provide a means for elucidating the mechanism of $\mathrm{O}_{2}$ reduction and explain some previously unanswered issues. 
The general scheme is given in Fig. 3. It has been written for alkaline solutions, but it can be easily transformed, mutatis mutandis, into an analogous scheme for acid solutions (33). The $k_{i}$ are overall rate constants for the ith step and subscripts $s a, a, b$ and * denote strongly adsorbed, weakly adsorbed, bulk and the vicinity of the disk electrode species, respectively. The scheme is a generalization of the schemes proposed so far and, as before, consists of two major paths by which $\mathrm{O}_{2}$ reduction can proceed. It treats however the direct path in a more complex manner (cf. rate constants $k_{3}$ and $k_{13}$ ), includes explicitly a superoxide ion $\mathrm{O}_{2, \mathrm{a}}^{-}$and the possibility has been allowed for the weakly adsorbed intermediates from the series path to undergo surface diffusion and form their strongly bound counterparts in the direct path.

The disk current for this scheme is given by

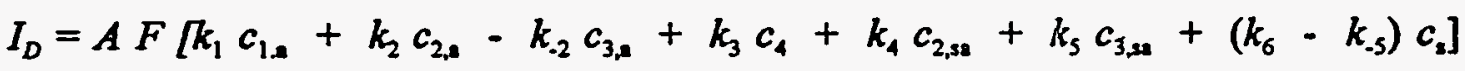

while the ring current is given by

$I_{\mathrm{R}}=n_{\mathrm{R}} A N F Z \omega^{1 / 2} \mathrm{c}_{3}$.

where $A$ is the disk area, $N$ is the collection efficiency, $n_{\mathrm{R}}$ is the number of electrons exchanged on the ring electrode, $\omega$ is frequency of rotation, $Z$ is a diffusion parameter for $\mathrm{HO}_{2}^{-}(Z=0.62$ $D^{2 / 3} / \mathrm{U}^{1 / 6}$, with diffusion coefficient $D$ and solution kinematic viscosity $\left.\mathrm{U}\right)$. The subscripts 1,2 , 3,4 , and 5 have been used for the $\mathrm{O}_{2}$ molecule, superoxide ion, hydrogen peroxide, oxygen atom and oxygen ion respectively. The criterion $N I_{\mathrm{D}} / I_{\mathrm{R}}$ vs. $\omega^{-1 / 2}$, used by Damjanovic et al. (42) to distinguish between direct and series paths, for the scheme in Fig. 3 has the following form $N I_{\mathrm{D}} / I_{\mathrm{R}}=2\left(1+A_{0}+A_{1} k_{-25} / Z \omega^{12}\right) / n_{\mathrm{R}}$

where $A_{0}$ and $A_{1}$ are complicated dimensionless functions of the rate constants (33).

The equation (12) has the linear dependence on $\omega^{-12}$, as for much simpler schemes which 
do not include the possibility of interactions between the direct and series paths. Any system with elementary path reactions that are first order with respect to the reactants, which has only one reaction taking place on the ring, would have a linear dependence of $N I_{D} / I_{R}$ on $\omega^{-1 / 2}$. This is a more sensitive criterion of the first order kinetics than the often used linearity of the KouteckyLevich plot (33). The non-linearity of the plot implies that some of the reactions involved are not first order, or that there is more than one reaction on the ring.

The so-called J - S plot, the criterion of Wroblowa et al. (47) for distinguishing between series and parallel paths, has the following form for the scheme in Fig. 3,

$J=2\left(1+A_{3}\right) / n_{\mathrm{R}}+Z S / k_{-2 S}$

where $\mathrm{J}$ is the intercept and $\mathrm{S}$ is the slope of an equation equivalent to the eq. 12 and $A_{3}$ is a complicated function of the reaction constants of Fig. 3. A non-linear J - S plot is obtained when the direct and series paths are coupled by surface diffusion of weakly bound intermediates. This explains experimentally found non-linear plots, not allowed in the previous criterion (32). In such a case, it is not possible on the basis of the $\mathrm{J}-\mathrm{S}$ plot to distinguish between a direct pathway with breaking of the $\mathrm{O}-\mathrm{O}$ bond and a pathway involving a strongly bound superoxide ion or a pathway which involves both. A linear plot is observed when the diffusion of the weakly adsorbed oxygen molecule and superoxide ions is slow and can be neglected $\left(k_{22}=k_{23}=0\right), k_{1}$ ) $k_{-20}$ and $k_{2} \gg k_{10}$. Linearity of the $\mathrm{J}-\mathrm{S}$ plot and the intercept with the J-axes, $\mathrm{J}>2 / n_{\mathrm{R}}$, is a characteristic of a true parallel pathway. In such a case the ratio of the direct to the series path can be evaluated. The $J-S$ plot is represented by a point when only a series pathway is operational which was found for $\mathrm{O}_{2}$ reduction on $\mathrm{Au}(111)$ in acid solution (49).

There is a considerable non-uniformity in the terminology for the reaction schemes of $\mathrm{O}_{2}$ 
reduction; in particular, the term "series" lacks precision. Anastasijevic et al. (33) proposed somewhat modified terms with one new "interactive" pathway resulting from their general scheme (cf. Fig. 3).

The following pathways can be defined:

i) a "direct" four-electron reduction to $\mathrm{H}_{2} \mathrm{O}$ (in acids), or to $\mathrm{OH}^{-}$(in alkalies) without hydrogen peroxide detected on the ring;

ii) a two-electron "series" pathway involving reduction to hydrogen peroxide;

iii) a "series" pathway with two- and four-electron reduction. In the case of only fourelectron reduction without hydrogen peroxide detected on the ring the case is indistinguishable from a "direct" four-electron reduction;

iv) a "parallel" pathway which is a combination of (i), (ii) and (iii); and

v) an "interactive" pathway in which diffusion of species from a "series" path into a "direct" path is possible.

Besides the reaction pathways, the detailed reaction mechanisms were analyzed in a major portion of the work in this area. There are several issues regarding the determination of the reaction mechanisms that are continuing to pose difficulties and are a source of disagreements. These are discussed below.

\subsection{Reaction on Platinum}

\subsubsection{Acid solutions}

Oxygen reduction on $\mathrm{Pt}$ and Pt-family metals occur by the parallel mechanism with 
predominantly direct four-electron reduction. The reduction to water, or to $\mathrm{OH}^{-}$in alkaline solutions, involves a breaking of the $\mathrm{O}-\mathrm{O}$ bond. The slow charge transfer step, which results in a $-120 \mathrm{mV}$ per decade (-2RT/F) slope, seems to be operative for several metal surfaces (at high current densities at $\mathrm{Pt}$ ) which seems to be generally accepted. This follows from a number of studies involving the disk-ring methodology $(1,50)$. The potential dependent intercept of the $I_{D}$ $/ I_{\mathrm{R}}$ vs. $\omega^{-1 / 2}$ plot yields the $\mathrm{J}-\mathrm{S}$ plot (cf. eqs. 12 and 13) with the intercept $\mathrm{J}>1$ (Fig. 4) which is indicative of a true parallel pathway.

The detailed mechanism of $\mathrm{O}_{2}$ reduction on surfaces supporting a four-electron reduction still defy determination. The number of possible mechanisms is high, given the possibility for the exchange of four electrons. In the case of a direct four-electron reduction, it is difficult to determine if the splitting of the $0-O$ bond takes place, or the reaction goes through the series pathway since peroxide is not detected on the ring electrode. Consequently, there is no way to determine the exact mechanism by the disk-ring methodology. Adzic et al. (51) used the inhibition of $\mathrm{O}_{2}$ reduction by silver adatoms deposited at UPD to determine whether the "bridge" configuration is operative in $\mathrm{O}_{2}$ adsorption on Pt. A large inhibition rate with increasing $\mathrm{Ag}$ coverage was indicative of a bridge adsorption of $\mathrm{O}_{2}$. For platinum and platinum group metals no, or very little, hydrogen peroxide is generated, probably when some adventitious impurities contaminated the electrode surface.

For these metals, there are two views regarding the first reaction step. The first is based on the early proposition by Damjanovic et al. (52) that the proton transfer occurs simultaneously with charge transfer, or protonation occurs in the fast homogenous or heterogenous chemical reaction following the charge transfer. In recent publications Sepa et al. $(11,53)$ reported an 
extensive study of the reaction on $\mathrm{Pt}$ in solutions of various $\mathrm{pH}$ with the data supporting this approach. For acid solutions, the mechanism that has been proposed is:

$$
\mathrm{O}_{2} \Rightarrow \mathrm{O}_{2} \text { (ads) }
$$

which is followed by the rate determining charge transfer,

$$
\mathrm{O}_{2} \text { (ads) }+\mathrm{H}^{+}+\mathrm{e}-\rightarrow \text { product(s) }
$$

The unusual Tafel slope of $-60 \mathrm{mV}(-\mathrm{RT} / \mathrm{F})$ and the reaction order of $3 / 2$ with respect to $\mathrm{H}^{+}$at low current densities were accounted for by assuming oxygen adsorption under Temkin conditions in the region of $\mathrm{PtOH}$ formation around $0.8 \mathrm{~V}$. At less positive potentials, the coverage of adsorbed oxygen-containing species becomes negligible, the kinetics becomes Langmuirian and the slope becomes $-120 \mathrm{mV}$, i.e. normal for reaction (15). The $\mathrm{pH}$ and pressure dependencies appear to support this mechanism. There is, however, no proof of the interaction of $\mathrm{O}_{2}$ with the oxygen-covered surface.

One of the key features of the mechanism of Damjanovic et al. is the relation of the "low" Tafel slope $(-60 \mathrm{mV})$ to the PtOH formation. Several workers proposed that $\mathrm{PtOH}$ is not the intermediate derived form the interaction of $\mathrm{O}_{2}$ with $\mathrm{Pt}$, but rather in the reaction of $\mathrm{H}_{2} \mathrm{O}$ with Pt and that it causes inhibition of $\mathrm{O}_{2}$ reduction $(54,55,56)$. No change of slope occurs at a $\mathrm{Pt}(111)$ surface in the presence of tetrahedral anions such as phosphate (54) and $\mathrm{HSO}_{4}^{-}$(28) which adsorb strongly on $\mathrm{Pt}(111)$ (57) and shift $\mathrm{PtOH}$ formation to $1.2 \mathrm{~V}$. A change of slope is observed for the other two low index planes in the same solutions. Adsorption of tetrahedral anions on these two planes is considerably lower than on $\operatorname{Pt}(111)(58)$ and they do not prevent PtOH formation around $0.8 \mathrm{~V}$. These results provide strong indirect evidence of the inhibitory effect of PtOH ( see section 6.1.4). 
The second view is advocated by Yeager and coworkers $(10,59,60$, who proposed that the most likely mechanism of the four-electron oxygen reduction on $\mathrm{Pt}$ involves dissociative chemisorption of the $\mathrm{O}_{2}$ molecule on a platinum surface. This probably occurs with simultaneous charge transfer. This view is corroborated by the lack of a hydrogen-deuterium kinetic isotope effect and also by the above mentioned effect of silver adatoms. Although there is evidence for dissociative chemisorption in gas phase adsorption of $\mathrm{O}_{2}$ (see section 3), there is no evidence for the cleavage of the $\mathrm{O}-\mathrm{O}$ bond in electrochemical systems. Yeager et al. list the following conclusions in favor of the dissociative adsorption of $\mathrm{O}_{2}$ as the rate controlling step:

1. Proton transfer is not involved in the rate determining step and it is not an important factor in $\mathrm{O}_{2}$ reduction kinetics in concentrated $\mathrm{H}_{3} \mathrm{PO}_{4}$.

2. The $\mathrm{O}_{2}$ competes with species in solution for adsorption sites. Adsorbed $\mathrm{Cl}, \mathrm{H}_{2} \mathrm{PO}_{4}^{-}, \mathrm{HSO}_{4}^{-}$ are particularly detrimental for kinetics of its reduction.

3. Additives which form self assembled ordered films on $\mathrm{Pt}$ may lower the $\mathrm{O}_{2}$ reduction overpotential. The decrease may be explained by increased $\mathrm{O}_{2}$ adsorption, since such an interface has a lower dielectric constant.

Two mechanisms given below meet these criteria. In each case the rate determining step is the adsorption of $\mathrm{O}_{2}$ on the $\mathrm{Pt}$ surface and the reaction is first order in $\mathrm{O}_{2}$ concentration $(10,58,59)$ 


\section{Mechanism I for $\mathrm{O}_{2}$ Reduction}

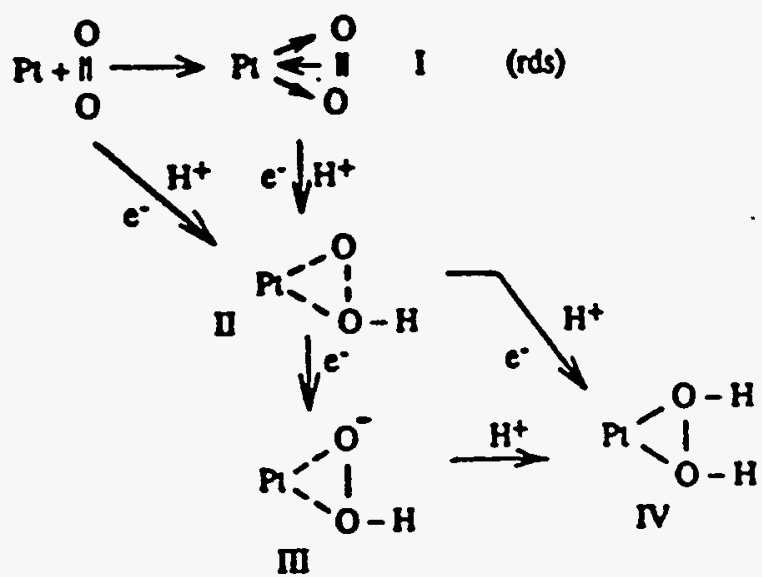

$(e, 1)$

(8. h)

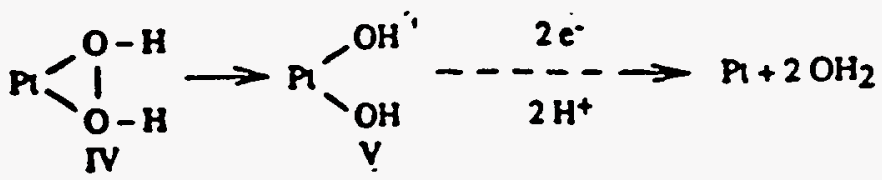

Mechanism II for $\mathrm{O}_{2}$ Reduction (dual site)

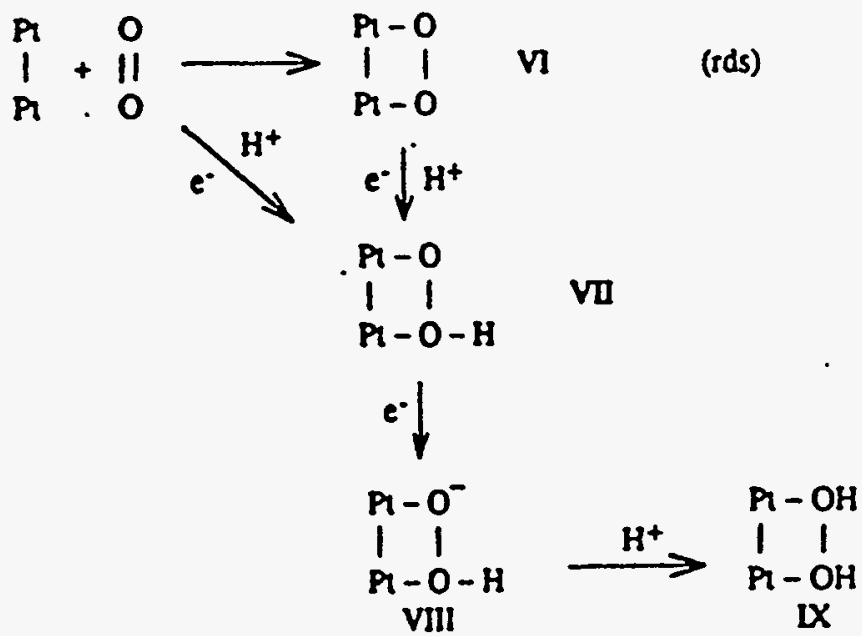

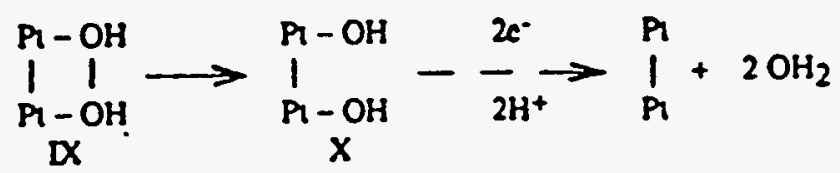


Anderson (61) proposed a model for predicting the $\mathrm{O}_{2}$ reduction mechanism based on calculation of adsorbate charges and adsorption energies for reaction intermediates using atom superposition and electron delocalization molecular orbital (ASED-MO) theory. The slow step for $\mathrm{O}_{2}$ reduction is predicted to be the displacement of $\mathrm{H}_{2} \mathrm{O}^{+}$or $\mathrm{OH}$ from the surface, shown for strontium ferrate.

In further studies of quantum chemical modeling of $\mathrm{H}_{2} \mathrm{O}(\mathrm{ads})$ decomposition to $\mathrm{OH}(\mathrm{ads})$, Anderson et al. (62) predict that $\mathrm{O}_{2}$ reduction on substitutional transition metal surface atoms in $\mathrm{Pt}$, such as $\mathrm{Pt}-\mathrm{Cr}, \mathrm{Pt}-\mathrm{Mn}, \mathrm{Pt}-\mathrm{Fe}, \mathrm{Pt}-\mathrm{Co}$ and $\mathrm{Pt}-\mathrm{Ni}$, are likely to be inactive toward oxygen because of blocking by the $\mathrm{OH}$ bound to them. Some experiments with similar alloys indicate an enhancement of the rate of $\mathrm{O}_{2}$ reduction (41).

The protonation of oxygen, which takes place in reactions with $\mathrm{H}^{+}$in acid, or with $\mathrm{H}_{2} \mathrm{O}$ in alkaline solutions, is another key feature of $\mathrm{O}_{2}$ reduction. Some authors assume that the protonation can occur before or simultaneously with the charge transfer to account for significant differences in the rate of the first charge transfer on various surfaces, since it should not depend strongly on the electrode material (63). It is also considered that an electron transfer can be followed by a fast homogenous or heterogenous protonation. The accelerating effect of additions of proton donors in non-aqueous solvents was interpreted as the effect of enhanced protonation of the $\mathrm{O}_{2}$ molecule (62). This stage is a source of major differences in the formulations of detailed mechanisms.

Because of the necessary protonation, Appleby (4) treated $\mathrm{O}_{2}$ reduction as a modified type of proton transfer reaction in an elaborate analysis using arguments as those for the ion-plus-atom reaction in $\mathrm{H}_{2}$ evolution. It is considered that the charge transfer to adsorbed species must be 
faster (smaller activation energy) than a full transfer across the double layer. Consequently, this cannot be the rate determining step (4). Any initial charge transfer to adsorbed oxygen molecules is supposed to be fast and not rate determining. This leaves a combined electron and proton transfer as the rate determining step or electron transfer to the $\mathrm{O}_{2}$ molecule in solution.

A theory has been developed based on this model combining the elements from transition state theory with radiationless electron transfer to simulate bond formation. The adsorbed hydrogen in this reaction may be either on a metal atom, or on another adsorbed atom or molecule. The treatment also assumes "a notional equilibrium" between forward and back reactions to facilitate the treatment of clearly irreversible $\mathrm{O}_{2}$ reduction. The expression for the exchange current density has a form similar to that for the corresponding exchange rate in electrochemical hydrogen evolution reaction. The ion-plus-atom reaction in $\mathrm{H}_{2}$ evolution and $\mathrm{O}_{2}$ reduction in acid solution, according to this approach, have the same pre-exponential factors. This effort represents a novel approach to the problem of oxygen reaction kinetics. It deserves further attention but some questions can be raised now.

It is difficult to reconcile a large difference in the rates of proton transfer and oxygen reduction. As a support of the theory, the rate of $\mathrm{O}_{2}$ reduction was compared with the rate of the ion-plus-atom reaction in hydrogen evolution. The latter reaction takes place on electrocatalysts with a poor activity for hydrogen evolution, such as $\mathrm{Ag}$, or $\mathrm{Au}$. A comparison with oxygen reduction on $\mathrm{Pt}$, the best electrocatalyst for $\mathrm{O}_{2}$ reduction, does not appear conclusive. The ionplus-atom reaction in $\mathrm{H}_{2}$ evolution on $\mathrm{Pt}$ induced by adlayer of $\mathrm{Pb}$ adatoms (64) (H-H recombination takes place on a clean $\mathrm{Pt}$ ) is in fact still several orders of magnitude faster than $\mathrm{O}_{2}$ reduction on $\mathrm{Pt}$. 
A lack of a significant inhibition of $\mathrm{O}_{2}$ reduction on $\mathrm{Pt}$ by submonolayer of $\mathrm{Pb}$ deposited at underpotentials suggests no similarity with the proton transfer $(65,66)$. By the same token, this observation does not support the view that the protonation is the source of the different activities of various materials for $\mathrm{O}_{2}$ reduction (62). Recent results of the hydrogen-deuterium isotopic studies of $\mathrm{O}_{2}$ reduction in $85 \%$ phosphoric acid by Yeager and coworkers (10) do not indicate any kinetic isotope effect which suggest that the protonation is not involved in the ratedetermining step.

Platinum as the best catalyst for $\mathrm{O}_{2}$ reduction is on the top of several volcano plots in the literature (67). Further enhancements of its activity is an interesting topic. Alloying of $\mathrm{Pt}$ with the first-row transition metal elements such as $\mathrm{V}, \mathrm{Cr}, \mathrm{Si}$ or $\mathrm{Ti}$ produced significant enhancement of the electrocatalytic activity of $\mathrm{Pt}$ for $\mathrm{O}_{2}$ reduction which has been explained by a more favorable $\mathrm{Pt}$ - $\mathrm{Pt}$ distance for $\mathrm{O}_{2}$ adsorption in alloys produced by contractions of the $\mathrm{Pt}-\mathrm{Pt}$ bond (68). Glass et al. (69) proposed a role of ordering of the alloy which affects the coverage of the $\mathrm{OH}(\mathrm{ads})$ on the surface. For the review see the article by Mukerjee (70). Recent investigations on five binary carbon-supported $\mathrm{Pt}$ alloy electrocatalysts $(\mathrm{Pt} / \mathrm{Cr}, \mathrm{Pt} / \mathrm{Mn}, \mathrm{Pt} / \mathrm{Fe}, \mathrm{Pt} / \mathrm{Co}, \mathrm{Pt} / \mathrm{Ni}$ ) using in situ X-ray absorption spectroscopy (XAS) revealed possible explanations of the enhanced activity of alloys in comparison with $\mathrm{Pt} / \mathrm{C}$ electrocatalyst. The electrochemical results were correlated with those obtained from XAS measurements which have provided information on the electronic, (Pt 5d-orbital vacancy, from X-ray near edge structure) and geometric (Pt-Pt bond distances, from the extended X-ray absorption fine structure) factors (41). The XAS results show that the alloys have higher Pt 5d-orbital vacancies and shorter Pt-Pt bond distances. These results also indicate that alloying inhibited the chemisorption of $\mathrm{OH}$ on the $\mathrm{Pt}$ at potentials above $0.8 \mathrm{~V}$. 
The current density measured at $0.9 \mathrm{~V}$ for $\mathrm{Pt} / \mathrm{Cr}$ alloy is $\sim 80 \mathrm{~mA} / \mathrm{cm}^{2}$, while for $\mathrm{Pt} / \mathrm{C}$ is $\sim 20 \mathrm{~mA} / \mathrm{cm}^{2}$. Fig. 5 shows Tafel plots for several selected alloys and Pt. Table 1 gives a comparison of the activation energy for $\mathrm{O}_{2}$ reduction with the results of the in situ EXAFS and XANES analysis. The XANES results at $0.54 \mathrm{~V}$ reveal higher $\mathrm{Pt}$ d-orbital vacancies for $\mathrm{Pt}$ alloys than for the $\mathrm{P} t \mathrm{C}$ electrocatalyst. At $0.84 \mathrm{~V}$, however, in contrast to the $\mathrm{Pt}$ alloys, the $\mathrm{Pt} / \mathrm{C}$ electrocatalyst exhibits a significant increase in the $\mathrm{Pt}$ d-orbital vacancies relative the value at $0.54 \mathrm{~V}$. The $\mathbf{P t}-\mathbf{P t}$ and Pt $-\mathrm{M}$ bond distances and coordination numbers showed no change with potential. For $\mathrm{Pt} / \mathrm{C}$ the coordination numbers were lower at $0.84 \mathrm{~V}$ due to the presence of chemisorbed $\mathrm{OH}$ species. EXAFS analysis showed no chemisorbed $\mathrm{OH}$ at this potential in the $\mathrm{Pt}$ alloys. These data indicate that the interplay of the electronic (higher Pt d-orbital vacancies) and geometric (shorter Pt - Pt bond distances) affects the $\mathrm{OH}$ chemisorption and kinetics of $\mathrm{O}_{2}$ reduction.

\subsubsection{Alkaline solutions}

The parallel mechanism is operative also for $\mathrm{O}_{2}$ reduction in alkaline solutions (1). Additional information on the mechanism of $\mathrm{O}_{2}$ reduction is usually sought from the pHdependence of the $\mathrm{O}_{2}$ reduction potential at constant current, $(\mathrm{dE} / \mathrm{dpH}$ ) over a wide $\mathrm{pH}$ range. There is no agreement regarding $\mathrm{pH}$ dependence in alkaline solutions (1). $\mathrm{dE} / \mathrm{dpH}$ at low current densities vary from -30 to $-60 \mathrm{mV}$, and from 0 to $-60 \mathrm{mV}$ at high current densities $(1,52,71,72)$. These differences lead to different reaction mechanisms. It appears that the reaction order with respect to $\left(\mathrm{OH}^{*}\right)$ is -1 , i.e., overpotential is independent of $\mathrm{pH}(4)$. The extent of electrocatalysis in alkaline solution appears to be smaller than in acid. Reaction is reasonably fast even on some materials (carbons) which show no formation of oxygenated adlayers. According to Appleby (4) 
the effects of electrocatalysis are negligible in these solutions since the alkaline medium acts as homogenous catalyst owing to the stabilizing effect on the reaction product, $\mathrm{HO}_{2}$. The exception to this appears to be Pt. Recent measurements on the low-index Pt single crystal surfaces however show structural dependence of reaction kinetics in alkaline solutions in the kinetic region (28). These results suggest that the reaction on $\mathrm{Pt}$ is "electrocatalytic" i.e., it involves interaction of the $\mathrm{O}_{2}$ molecule with the electrode surface. The potential range of $\mathrm{M}-\mathrm{OH}$ formation on platinum metals in alkaline solutions is considerably wider than in acid solutions. Consequently, the $60 \mathrm{mV}$ slope is extended to less positive potentials.

The slow charge transfer step in alkaline solutions can be linked to the splitting of the 0 $\mathrm{O}$ bond, or in the reaction with $\mathrm{H}_{2} \mathrm{O}$, equivalent to the protonation in acid solutions,

$$
\mathrm{O}_{2} \text { (ads) }+\mathrm{H}_{2} \mathrm{O}+\mathrm{e} \rightarrow \mathrm{HO}_{2} \text { (ads) }+\mathrm{OH}^{-} \rightarrow \text { products }
$$

In addition to these reactions, $\mathrm{O}_{2}$ reduction can yield $\mathrm{O}_{2}^{-}$by a heterogenous outer-sphere charge transfer (2),

$$
\mathrm{O}_{2} \text { (ads) }+\mathrm{e} \rightarrow \mathrm{O}_{2}^{\cdot} \text { (ads) } \rightarrow \text { products }
$$

The reorganizational free energy of activation should be small for these two species since there is only a small change in the bond lengths upon reaction (from 1.20 to $1.28 \AA$ ). Because of a more negative standard electrode potential for the $\mathrm{O}_{2} / \mathrm{O}_{2}^{-}$couple $\left(\mathrm{E}_{0}=-0.3 \mathrm{~V}\right)$ than that for $\mathrm{O}_{2} / \mathrm{HO}_{2}^{-}$ couple $\left(E_{0}=-0.065 \mathrm{~V}\right)$, the outer-sphere electron transfer may become a competing process only at high overpotentials (1).

\subsubsection{Reaction on Gold}

Oxygen reduction on $\mathrm{Au}, \mathrm{Hg}$ and various carbon materials involves a two-electron 
reaction with hydrogen peroxide as the reaction product. Gold appears to be the unique metal which, in addition to a two-electron reduction, supports a four-electron reduction. The latter occurs only on the $\mathrm{Au}(100)$ single crystal face and its vicinals in alkaline solutions (see section 6.1). Detailed mechanistic studies of the reactions on gold (73) and carbon (74) were reported. Reaction mechanisms for surfaces supporting only a two-electron reduction appear better established than the mechanisms for a four electron reduction (1). For example, two mechanisms were proposed for $\mathrm{O}_{2}$ reduction on gold which differ in one reaction step. Tarasevich and coworkers proposed (73) the $\mathrm{O}_{2}$ adsorption

$$
\mathrm{O}_{2} \rightarrow \mathrm{O}_{2} \text { (ads) }
$$

to be rate determining, followed by a charge transfer and peroxide formation,

$$
\begin{aligned}
& \mathrm{O}_{2} \text { (ads) }+\mathrm{e} \rightarrow \mathrm{O}_{2}^{-} \text {(ads) } \\
& \mathrm{O}_{2}^{-} \text {(ads) }+\mathrm{H}_{2} \mathrm{O}+\mathrm{e} \rightarrow \mathrm{HO}_{2}^{-}+\mathrm{OH}^{\circ}
\end{aligned}
$$

Zurilla et al. (72) proposed the mechanism with the first step combining reactions (18) and (19) into a single step,

$$
\mathrm{O}_{2}+\mathrm{e} \rightarrow \mathrm{O}_{2}^{-} \text {(ads) }
$$

which is followed by a surface dismutation reaction,

$$
2 \mathrm{O}_{2}^{-} \text {(ads) }+\mathrm{H}_{2} \mathrm{O}=\mathrm{O}_{2}+\mathrm{HO}_{2}^{-}+\mathrm{OH}^{-}
$$

Rotating disk-ring measurements, stoichiometric numbers determinations, and isotopic oxygen labeling experiments facilitated a determination of the reaction mechanisms and reaction schemes discussed above. 


\section{Surface Structure and Reaction Kinetics}

\subsection{Gold}

Studies of the kinetics of electrocatalytic reactions on well-ordered single crystal surfaces in clean solutions opened up a new dimension in the area of electrocatalysis and a possibility for a deeper understanding these reactions. This can facilitate establishing a correlations between the surface structure and reaction kinetics. The flame annealing procedure (75) for preparation of single crystal surfaces gives well ordered surfaces which rival the preparation in UHV. With adequate protection by a drop of ultra pure water, or with a monolayer of adsorbate which can be desorbed, the transfer can be carried out without contamination. In some cases the adsorbates to be studied can protect the surface from contamination. Surprising effects of the surface structures were found with several electrochemical reactions, including $\mathrm{O}_{2}$ reduction. Some of the properties observed with a particular face could not be inferred from the data for polycrystalline surfaces. The use of novel structure-sensitive techniques capable of giving information on the surface structure during the course of reactions appears particularly important. This fulfills the long lasting dream to monitor the surface structure under "operating conditions".

\subsubsection{Alkaline Solutions}

$\mathrm{O}_{2}$ reduction on $\mathrm{Au}$ in alkaline solutions represents one particularly interesting example of a structure sensitive reaction. Besides striking structure dependent kinetics observed for the low index planes (76) and for several stepped surfaces (77), the reaction mechanism was shown to be structure dependent. The four-electron reduction is observed for $\mathrm{Au}(100)$ and its vicinals 
only in the limited potential region of the existence of chemisorbed $\mathrm{AuOH}^{(1-\lambda)}$ adlayer. Outside this potential region, as well as in the whole potential region except extreme overpotentials for the other two low index planes, a two-electron process is operative. The $A u(100)$ surface is the most active catalyst for $\mathrm{O}_{2}$ reduction in alkaline solutions, it surpasses even the activity of $\mathrm{Pt}$. McIntyre and Peck (78) and Taylor et al. (79) confirmed these findings. Fig. 6 displays voltammetry curves for the three low index planes. The reaction on $A u(100)$ is shifted to considerably more positive potentials in comparison with the other two low index planes. Besides this, a four-electron reduction is operative only for this plane in the kinetic region.

The reaction mechanism was proposed by Adzic et al. $(39,75)$. The first charge transfer is the rate determining step for all three planes with the first two steps given by equations (23) and (24) for polycrystalline $\mathrm{Au}$. For $\mathrm{Au}(100)$, further reactions involve probably a direct reduction of $\mathrm{HO}_{2}^{-}$to $\mathrm{OH}^{-}$. For the other two surfaces the reaction stops at the peroxide stage. Tafel slopes are $-120 \mathrm{mV}$, the reaction order in the $\mathrm{O}_{2}$ concentration is 1 , and in $\mathrm{HO}_{2}^{-}$is zero. The rotating disk-ring measurements were reported by Strbac et al. for the $A u(100)$, vicinal $A u(910)$ and $\mathrm{Au}(11,1,1)(80)$ and $\mathrm{Au}(311)(76)$ planes. $\mathrm{No}^{-\mathrm{HO}_{2}}$ is detected on the ring in the potential region between -0.2 and $0.1 \mathrm{~V}$ where an $\mathrm{AuOH}^{(1-2) \text { - }}$ adlayer is present on the surface (Fig.7). Based on the analysis using the scheme given in Fig. 3, the following conclusions were reached. At more negative potentials, as $\theta_{\mathrm{AuOH}(1-\lambda)} \rightarrow 0$, a four electrode reduction takes place in an interactive pathiway. At somewhat more negative potentials, when $\theta_{\text {AuOH(1-x). }}=0$, a two electron series pathway is operative, and at extreme overpotentials, a four-electron series pathway occurs. For vicinal faces, the region of the four-electron reduction is reduced because of a narrower region of the $\mathrm{AuOH}^{(1-\lambda)}$ formation. In the potential range from -0.30 to $-0.45 \mathrm{~V}$, the corresponding $\mathrm{J}$ - 
$S$ plot is non-linear, indicating interaction between the series and direct pathways (33). From 0.55 to $-0.65 \mathrm{~V}$, diffusion control sets in and the slope $\mathrm{S} \rightarrow 0$, indicating no adsorption -desorption equilibrium of $\mathrm{HO}_{2} \cdot\left(\mathrm{k}_{-25}=0\right)$, i.e. a two-electron series is operative. At potentials negative of $0.65 \mathrm{~V}$, the $\mathrm{J}-\mathrm{S}$ plot is linear with an intercept $\mathrm{J}=1$, indicating the overall series mechanism $\left(k_{21}=k_{22}=k_{23}=0\right)(79)$.

An interesting result of the analysis using the general scheme is evidence of the surface diffusion of $\mathrm{HO}_{2}^{-}$. From the slope $\mathrm{S}$ for this scheme,

$S=k_{.25}\left(k_{11}+2 k_{24}\right) / n R Z_{2} k_{25}$

assuming that the catalytic decomposition of $\mathrm{HO}_{2}^{-}\left(\mathrm{k}_{11}\right)$ is independent of the potential (33), the change of slope with potential is due to the dependence of the surface diffusion of $\mathrm{HO}_{2}^{-}$on the potential, $k_{24}=f(E)$, i.e.

$\partial \log S / \partial E=\delta \log k_{24} / \partial E=120 \mathrm{~s}^{-1} \mathrm{mV}^{-1}$

which agrees with the experiment (79). The surface diffusion of $\mathrm{HO}_{2}^{-}$is difficult to verify experimentally. However, it is possible that the surface mobility of charged species such as $\mathrm{HO}_{2}{ }^{\circ}$ is potential dependent.

Anastasijevic et al. (30) proposed mapping the fluxes of $\mathrm{O}_{2}$ reduction through different reaction pathways. The map can be calculated from the disc and ring currents for the whole potential region where $I_{R}>0$. The fraction of the two-electron series pathway can be calculated from the equation,

$\mu=\left[I_{\mathrm{R}}(E) n_{\mathrm{D}} / N I_{\mathrm{D}}(E) n_{\mathrm{R}}\right] 100 \%$

Exceptional activity of $\mathrm{Au}(100)$ and its vicinals with large terraces was addressed by Strbac (81). The four-fold symmetry of the (100) orientation seems to be suitable for a strong 
chemisorption of $\mathrm{OH}^{-}$resulting in a larger coverage and discharge than on other faces $\left(120 \mu \mathrm{C} / \mathrm{cm}^{2}\right.$ on $\mathrm{Au}(100)$, but only $15 \mu \mathrm{C} / \mathrm{cm}^{2}$ on $\left.\mathrm{Au}(111)\right)$. It was proposed that the AuOH${ }^{(1 \cdot 2)-}$ adlayer enables dissociative adsorption of $\mathrm{O}_{2}$ and chemisorption of $\mathrm{O}_{2}$ and $\mathrm{HO}_{2}^{-}$which makes possible the transfer of four electrons from a 6 s energy level of $A u$ to the $\pi^{*}-\mathrm{MO}$ and $\sigma^{*}-\mathrm{MO}$ of $\mathrm{O}_{2}$ at lower energy. Without $\mathrm{AuOH}^{(1-\lambda)}$, only a transfer of two electrons is possible $\left(\mathrm{HO}_{2}^{-}\right.$ formation) since ${ }^{*} \sigma-\mathrm{MO}$ of $\mathrm{O}_{2}$ are higher in energy than 6 s levels of $\mathrm{Au}$ (82). A strong indication for a dissociative adsorption of $\mathrm{O}_{2}$ is found in the fact that the reduction on $\mathrm{Au}(100)$ commences at $0.380 \mathrm{~V}$ (S.H.E.) which is very close to $0.401 \mathrm{~V}$ (S.H.E.), the standard equilibrium potential for the four electron reduction in alkaline solutions. At potentials close to $0.380 \mathrm{~V}$, the reduction of $\mathrm{HO}_{2}^{-}$on $\mathrm{Au}$ does not occur. In fact, at that potential the $\mathrm{HO}_{2}^{-}$oxidation takes place, and the fourelectron direct reduction seems to be the thermodynamically favorable reaction. At lower potentials, where the reduction of $\mathrm{O}_{2}$ to $\mathrm{HO}_{2}^{-}$is possible, the AuOH${ }^{(1-\lambda)}$ adlayer acts as a precursor for $\mathrm{HO}_{2}^{-}$chemisorption, thus catalyzing its further reduction to $\mathrm{OH}^{-}$in a series fourelectron reduction of $\mathrm{O}_{2}$.

McIntyre and Peck (77) attributed the activity of $\mathrm{Au}(100)$ for a four-electron reduction to its four-fold symmetry and a two-electron reduction to the reaction on the reconstructed, "hex" surface with hexagonal overlayer (83) which is likely to behave similarly to the Au(111) surface. This explanation, however, cannot account for the two-electron reduction on $\mathrm{Au}(100)$ at potentials at which the surface is not reconstructed and $\mathrm{AuOH}$ is not formed, as in acid solutions. Polewska et al. (84) using in situ STM, and Markovic et al. (85) using in situ X-ray diffraction techniques concluded that the change from unreconstructed ( $1 \times 1)$ surface to reconstructed "hex" structure is not responsible for a change in a number of exchanged electrons. As previously proposed (23), 
the $\mathrm{AuOH}^{(1-\lambda)}$ adlayer has a key role in the four-electron reduction on $\mathrm{Au}(100)$. Models for interaction of $\mathrm{O}, \mathrm{OH}, \mathrm{O}_{2}$ and $\mathrm{HO}_{2}^{-}$with the $\mathrm{Au}(100)$ surface show the possibility for $\mathrm{O}_{2}$ or $\mathrm{HO}_{2}^{-}$ to enter the four-fold symmetry hole formed on this surface. This does not exist for the three-fold symmetry hole on $\mathrm{Au}(111)$ because of steric hindrances, and this surface is completely inactive for $\mathrm{HO}_{2}^{-}$reduction. A special role of $\mathrm{AuOH}$ in determining the activity of $\mathrm{Au}(100)$ warrants further study which may provide some information for designing new catalysts. Unfortunately, gas phase measurements of hydroxyl adsorption on $\mathrm{Au}(100)$ are at present unavailable.

Strbac et al. (49) have examined the reaction on 14 different stepped surfaces. Steps increased the activity of $A u(111)$. This enhancement increased with the step density. The surfaces vicinal to $A u(100)$ show a characteristic four-electron reduction only if they are composed of very long (100)-oriented terraces, i.e., if their orientation is close to the (100) axis.

\subsubsection{Acid solutions}

Oxygen reduction on gold in acid solutions is a very slow process. It is, however, strongly structure dependent. Alvarez-Rizzatti and Juttner (24) have shown higher activity of Au(100) than that of the other low-index planes. Two-electron reduction and the first electron-transfer rate determining step were common for all faces. This has been confirmed in references (77) and (49). Vicinals to $\mathrm{Au}(111)$ display a considerably higher activity than flat Au(111).

Disk-ring measurements were reported by Strbac et al. (86). The J-S plot for the Au(111) surface is a point, as derived from the general scheme for the series pathway yielding $\mathrm{H}_{2} \mathrm{O}_{2}$ as the reaction product. For all surfaces investigated the Tafel slope was approximately $-120 \mathrm{mV}$. The measurements of Strbac et al. (49) with stepped surfaces showed a systematic variation of 
the half-wave potential with step density. A correlation of the overpotential at a constant current with the calculated surface energy has been found for all the orientations investigated except for Au(100) (Fig. 8) (87). Evidently, the structural factor for this particular orientation outweighs the electronic factor. For other surfaces the correlation appears satisfactory and, with this exception, it can be used to predict the catalytic activity of gold surfaces.

\subsubsection{Silver}

Zwetanova and Juttner (88) found no difference in the activity of low-index $\mathrm{Ag}(\mathrm{hkl})$ surfaces either in acid or in alkaline solutions. Isakovic and Adzic (89) found at least a $50 \mathrm{mV}$ difference in half-wave potentials in acid solutions. The activity in acid solutions decreased in the following sequence: $\operatorname{Ag}(111)>A g(100)=A g(110)$. In alkaline solutions, the $A g(100)$ plane exhibited the highest activity, while $\mathrm{Ag}(110)$ again exhibited the lowest activity. Four-electron reduction was found with all three surfaces investigated. McIntyre and Peck (77) also reported a small difference in the activity of $\mathrm{Ag}$ surfaces. The poisoning of $\mathrm{Ag}(100)$ could, if not recognized, mask the higher activity of this surface. The first electron exchange is the ratedetermining step for all surfaces.

The large difference between the activities of gold and silver surfaces, except $A u(100)$ is clearly a consequence of the different electronic structures of the two metals. As mentioned above, gold is very inactive for adsorption of $\mathrm{O}_{2}$ from the gas phase. However, both molecular and atomic oxygen coexist on $\mathrm{Ag}(111)$ at room temperature (cf. section 3). Molecular orbital considerations show that end-on adsorption of $\mathrm{O}_{2}$ is expected on $\mathrm{Au}$, while for $\mathrm{Ag}$ bridge adsorption should be more favorable in agreement with the observed four-electron reduction (81). 
The 5s-level of silver is higher in energy than the $\sigma_{2}{ }^{*}$-orbital of the $\mathrm{O}_{2}$ molecule. A transfer of four electrons from the $5 \mathrm{~s}$-level of $\mathrm{Ag}$ to the $\pi^{*}$ - and $\sigma_{2}{ }^{*}$-levels of oxygen is energetically possible. The $\mathrm{O}_{2}$ interaction with silver electrode surfaces warrants further attention.

\subsubsection{Platinum}

Ross (90) has found no effect of crystallographic orientation on the reaction in $\mathrm{O}_{2}$ reduction on several single crystal electrodes. Markovic et al. (27) demonstrated small structural effects in $\mathrm{HClO}_{4}$ solution by using a hanging meniscus rotating disk electrode. Fig. 8 shows voltammetry curves obtained with HMRD electrodes with three low index planes of Pt. The activity of $\mathrm{Pt}$ faces, considering a half-wave potentials, decreases in the order $\mathrm{Pt}(110)>\mathrm{Pt}(111)$ $>\mathrm{Pt}(100)$. A four-electron reduction is found for all three faces except for $\mathrm{Pt}(111)$ in the hydrogen adsorption region where the reaction was close to a two-electron reduction. Tafel slopes of $-120 \mathrm{mV}$ at high current densities and $-60 \mathrm{mV}$ at low current densities are observed in each case . at room temperature. The potential of the intersection of the two slopes is also crystal face dependent. The change of the slope for Pt(111) occurs, not at the so-called "butterfly" peak associated with $\mathrm{PtOH}$ formation, but at the second peak for $\mathrm{PtOH}$. This corroborates the previous discussion (section 5.1) that the change of slope is caused by the blocking effect of PtOH rather than by the Temkin adsorption of $\mathrm{O}_{2}$ on Pt. More positive potentials and the change of the state of PrOH adsorbate with increase in coverage produced a change in Tafel slope. Some kinetic parameters for $\mathrm{O}_{2}$ reduction on $\mathrm{Pt}$ single crystal electrodes in $\mathrm{HClO}_{4}$ solutions are given in Table 2.

In phosphoric acid solutions, however, Tanaka et al. (91) showed pronounced structural 
effects on $\mathrm{O}_{2}$ reduction with the following sequence in activity: $\operatorname{Pt}(110)>\operatorname{Pt}(100)>\operatorname{Pt}(111)$. Strong adsorption of tetrahedral phosphoric acid anions on $\mathrm{Pt}(111)$, which shifts $\mathrm{O}_{2}$ reduction to more negative potentials than on the other two planes was proposed as an explanation of the observed sequence. In $0.1 \mathrm{M} \mathrm{H}_{3} \mathrm{PO}_{4}$ only a single slope of $-120 \mathrm{mV}$ was observed for $\mathrm{Pt}(111)$. This is explained by the absence of $\mathrm{PtOH}$ formation up to $\mathrm{E}>1.2 \mathrm{~V}$ caused by anion adsorption (cf. section 5.1). These data also strongly suggest the inhibitory effect of a $\mathrm{PtOH}$ layer on $\mathrm{O}_{2}$ reduction. Durand et al. (92) showed almost no structural effect in $\mathrm{HClO}_{4}$ solution, but found considerable effects in $\mathrm{H}_{2} \mathrm{SO}_{4}$ and $\mathrm{HCl}$ solutions. The latter effects were ascribed to the adsorption of anions rather than to the effects of the surface symmetry. These experiments were carried out without mass transport control. Durand et al. (93) repeated their experiments with a hanging meniscus rotating electrode. Kita et al. (94) reported no structural sensitivity from measurements with stationary electrodes. The chemical reaction of $\mathrm{O}_{2}$ with adsorbed $\mathrm{H}$ was ruled out as a possible explanation for the decrease of the diffusion limiting current for Pt(111). The blocking effect of the UPD hydrogen is assumed with reaction occurring at imperfections. The Tafel slopes of $-90 \mathrm{mV}$ that these authors observed are lower than the value reported by other workers.

Most recently, Markovic et al. (28) succeeded in assembling a disk-ring rotating Pt single crystal electrode without noticeable contamination. This opens interesting possibilities for studying $\mathrm{O}_{2}$ reduction and other reactions on $\mathrm{Pt}$ single crystal electrodes. The disk-ring preliminary data confirmed the structural sensitivity of $\mathrm{O}_{2}$ reduction on $\mathrm{Pt}$ in $\mathrm{H}_{2} \mathrm{SO}_{4}$ and $\mathrm{HClO}_{4}$ solutions. A single slope $(-120 \mathrm{mV})$ for the reaction on $\mathrm{Pt}(111)$ in $\mathrm{H}_{2} \mathrm{SO}_{4}$ solutions (two slopes for $\mathrm{Pt}(110)$ and $\mathrm{Pt}(100)$ ) was explained by the shift of $\mathrm{PtOH}$ formation to $1.2 \mathrm{~V}$ caused by 
bisulfate adsorption (Fig. 10). See also Figs. 9 and 11. A strong bisulfate adsorption on Pt(111) (56) and a very small adsorption on the other two low-index planes (57) was confirmed by FTIR. Therefore, the two slopes for three faces in non-adsorbing perchloric acid solutions, and a single slope for $\mathrm{Pt}(111)$ in solutions with strongly adsorbed bisulfates and phosphates on $\mathrm{Pt}(111)$, provide evidence for the inhibitory effect of $\mathrm{PtOH}$ on $\mathrm{O}_{2}$ reduction.

The disk-ring measurements of $\mathrm{O}_{2}$ reduction on $\mathrm{Pt}(111)$ electrode are shown with more details in Fig. 11. Practically no $\mathrm{H}_{2} \mathrm{O}_{2}$ generation except in the $\mathrm{H}_{2}$ adsorption region is observed. The inhibition of the reaction in the region of hydrogen adsorption is the most pronounced on $\mathrm{Pt}(111)$, causing a quantitative generation of $\mathrm{H}_{2} \mathrm{O}_{2}$ detected on the ring electrode. Therefore, this experiment shows that $\mathrm{O}_{2}$ reduction takes place at $\mathrm{H}$-covered $\mathrm{Pt}(111)$, but as a two-electron process, rather than on surface imperfections mentioned above. The data also indicate the difference between the state of adsorbed $\mathrm{H}$ on $\mathrm{Pt}(111)$ and the other two low index planes.

\section{Surfaces modified by foreign metal adatoms}

Foreign metal adatoms cause remarkable catalytic effects on oxygen reduction on gold electrodes. The reaction mechanism changes from a two-electron reduction on Au to a fourelectron reduction on Au covered with several metal adatoms deposited at underpotential in alkaline solutions. A series mechanism was found for $\mathrm{Au} / \mathrm{Pb}, \mathrm{Au} / \mathrm{Bi}$ and $\mathrm{Au} / \mathrm{Tl}$ systems. $\mathrm{H}_{2} \mathrm{O}_{2}$ reduction is catalyzed on the surface covered by metal adlayers. The work mostly done with polycrystalline surfaces was reviewed by Adzic (95) and Kokkinidis (96).

Structural studies of metal adlayers were reported for several systems during the course of $\mathrm{O}_{2}$ reduction. $\mathrm{Tl}$ causes a four-electron reduction in a kinetic reduction region only. At more 
negative potentials, the reaction reverts back to a two-electron reduction. The in-plane X-ray diffraction measurements revealed that the close-packed rotated-hexagonal $\mathrm{Tl}$ phase supports a two-electron reduction. The lower coverage $\mathrm{Tl}$ phases which exist at more positive potentials, viz., the aligned hexagonal phase (Fig. 12) in alkaline solution and patches of the $(2 \times 2)$ phase in acid solution, are conducive to a four-electron reduction. The latter phase was not reproducible, its patches were observed by STM. $\mathrm{O}_{2}$ reduction does not change the $\mathrm{Tl}$ coverage in the closepacked hexagonal phase, but causes a significant decrease of the in-plane diffracted intensity (Fig.13). The diffraction intensity from the low coverage phases vanishes during $\mathrm{O}_{2}$ reduction. It appears from $x$-ray specular reflectivity that the $T$ l coverage remains on the surface. These observations indicate that the $\mathrm{O}_{2}$ molecules interact directly with the $\mathrm{Tl}$ adatoms prior to the charge transfer. This provides the most direct evidence that the outer sphere charge transfer mechanism in $\mathrm{O}_{2}$ reduction is not operative for some surfaces. $\mathrm{H}_{2} \mathrm{O}_{2}$ reduction is facile on the surface covered with the low-coverage $\mathrm{Tl}$ phases, while it is almost completely suppressed by the rotated-hexagonal phase. It appears that the low $\mathrm{Tl}$ coverage and $\mathrm{O}_{2}$ interaction with $\mathrm{Au}$ and $\mathrm{Tl}$, rather than the well defined structure, are critical for a four-electron reduction (97).

Gewirth and coworkers reported structural studies of $\mathrm{Pb}(37)$ and $\mathrm{Bi}(98)$ adlayers on $\mathrm{Au}(111)$ during $\mathrm{H}_{2} \mathrm{O}_{2}$ reduction. The $(2 \times 2)-\mathrm{Bi}$ structure was identified in the potential region at which a maximum activity for $\mathrm{H}_{2} \mathrm{O}_{2}$ reduction is observed. A heterobimetalic bridge model for $\mathrm{H}_{2} \mathrm{O}_{2}$ interaction with this surface is assumed as the explanation of the enhanced catalytic activity. The rectangular, high coverage $\mathrm{Bi}$ phase is not catalytically active for $\mathrm{H}_{2} \mathrm{O}_{2}$ reduction. The highest activity for the $\mathrm{Au}(111) / \mathrm{Pb}$ surface was observed when the surface was maximally covered by the $\mathrm{Pb}$ islands. 
Abe et al. (99) observed a total inhibition of $\mathrm{O}_{2}$ reduction on $\mathrm{Au}(111)$ by a $\mathrm{Cu}$ adlayer in the potential region where $\mathrm{Cu}$ forms a honeycomb $(\sqrt{3} \times \sqrt{3}) \mathrm{R} 30$ structure in the absence of $\mathrm{O}_{2}$. In contrast to the inhibitory effect of $\mathrm{Cu}$ adatoms, the reaction on bulk $\mathrm{Cu}$ is the two-electron process. Sulfate/bisulfate is adsorbed in a center of honeycomb (100) which could be the cause of the inhibition.

Cu submonolayer formed in the first UPD peak on $\mathrm{Pt}(111)$ causes inhibition by decreasing the current to approximately one half, while a $\mathrm{Cu}$ monolayer causes a complete inhibition (Fig. 14) (101) The reduction of $\mathrm{O}_{2}$ to $\mathrm{H}_{2} \mathrm{O}_{2}$ is assumed in the presence of either the simple, or honeycomb $(\sqrt{3} \times \sqrt{3}) \mathrm{R} 30^{\circ}$ structure, as concluded from the in situ STM measurements. The latter structure was inferred from chronocoulometric measurements (102).

As discussed above, determination of the adlayer structures with scanning probes during the course of the reactions is severely limited by a thin layer cell between the tip and the imaged area. Therefore, the adlattices established by in situ scanning probes during the course of reactions can be taken as possible structures that exist on the surface during $\mathrm{O}_{2}$ reduction. They probably are not well ordered during the reaction, but the coverage may be unchanged. This is strongly suggested by the X-ray diffraction measurements.

Machado et al. (65) measured $\mathrm{O}_{2}$ reduction on $\mathrm{Pt}$ covered with a $\mathrm{Pb}$ adlayer with a rotating disk-ring electrode technique. It is interesting that $\mathrm{Pb}$ at low coverages does not cause significant inhibition of a four-electron reduction in the kinetic region, in agreement with earlier preliminary data $(50,103)$. A change of the mechanism to the series four-electron reduction may be possible in this potential region, but no $\mathrm{H}_{2} \mathrm{O}_{2}$ is detected on the ring to provide an answer to this question. At larger $\mathrm{Pb}$ coverages, in the diffusion control region of $\mathrm{O}_{2}$ reduction, the 
inhibition is observed and $\mathrm{H}_{2} \mathrm{O}_{2}$ is detected on the ring (Fig. 15). The inhibition was explained by linear adsorption of $\mathrm{O}_{2}$ on the $\mathrm{Pt} / \mathrm{Pb}$ surface which results in reduction to $\mathrm{H}_{2} \mathrm{O}_{2}$. In this potential region $\mathrm{Pb}$ forms on $\mathrm{Pt}(111)$ a high coverage phase, $\theta=2 / 3$ and the unit cell $4 \mathrm{~Pb}-(3 \mathrm{x}$ $\sqrt{3}$ ) (104). This adlayer leaves a very small hole between $\mathrm{Pd}$ adatoms for the interaction of $\mathrm{O}_{2}$,

or $\mathrm{H}_{2} \mathrm{O}_{2}$ with $\mathrm{Pt}$. The hole width is $0.65 \AA$ (the diameter of $\mathrm{O}$ atom is $0.66 \AA$ ) which may not be large enough for an $\mathrm{O}_{2}$ molecule to reach the underlying $\mathrm{Pt}$ atoms for a part of the surface with this orientation. These data also strongly suggest that proton transfer in $\mathrm{O}_{2}$ reduction, involving any kind of $\mathrm{H}$ interaction with the surface, is not likely to occur (cf. section 5).

Pronounced catalytic effects are caused by $\mathrm{Tl}$ and $\mathrm{Pb}$ adsorbates on $\mathrm{Ru}$ or $\mathrm{Ru}$ oxide electrodes in alkaline solutions. $\mathrm{Tl}$ and $\mathrm{Pb}$ cause change of the $\mathrm{Ru}$ or $\mathrm{Ru}$ oxide surface (the latter is completely inactive for $\mathrm{O}_{2}$ reduction)by giving rise to a four-electron reduction with the first charge transfer rate determining step (105). Traces of $\mathrm{Tl}$ or $\mathrm{Pb}$ were sufficient to produce catalytic effects. $\mathrm{Tl}$ and $\mathrm{Pb}$ cations interact with $\mathrm{Ru}$ oxide and cannot be removed by anodic polarization. This system differs considerably from the usual UPD.

Catalytic effects of metal adatoms formed by UPD may have some applicative potential in energy conversion and in particular in avoiding higher corrosion rates by preventing UPD in systems where it can occur. Besides that, these systems offer interesting information regarding $\mathrm{O}_{2}$ interaction with metal surfaces and regarding the $\mathrm{O}_{2}$ reactivity in relation to the surface structural and electronic properties.

\section{Non-noble Metals and Oxides}

Oxygen reduction on non-noble metals attracted considerable attention recently, primarily 
because of its role in corrosion. Oxygen reduction on bare iron in neutral solutions has been interpreted in terms of the first charge transfer rate determining step in a direct four-electron reduction in borate buffers, pH 7 - 10 (106). A four-electron reduction was also observed by Zecevic et al. (107) with very little $\mathrm{H}_{2} \mathrm{O}_{2}$ being formed. On the oxidized surface, including the passive one, the series mechanism was found to be operative, while no distinction between parallel and series mechanisms could be made on the oxide-free surface. At oxide-free surfaces all processes are faster than at the oxide-covered surfaces. This can be explained by assuming the mediation of the surface $\mathrm{Fe}$ (II) sites formed by reduction of the passive film which act as oxygen adsorption centers. Such a possibility has been suggested by Presnov and Trunov (108) and further elaborated by Calvo and Schiffrin (109). For the reaction on passive iron in near neutral solutions two rate determining steps were reported: the oxygen chemisorption under Temkin conditions (103) and a first electron transfer (104). The transfer coefficients were found to be $\alpha=0$ (chemical rate determining step) and $\alpha \approx 0.5$. For reaction in alkaline solutions, Calvo and Schiffrin (106) and Zecevic et al. (110) proposed the same role of the Fe(II) surface species as in ref. (105). Two different rate determining steps were proposed, viz, the reduction of adsorbed peroxide (106) and adsorption of $\mathrm{O}_{2}$ (107). Vago and Calvo (111) reported similar kinetics on $\mathrm{Fe}_{3} \mathrm{O}_{4}$ surfaces in alkaline solutions to those of other iron oxides, emphasizing the role of $\mathrm{H}_{2} \mathrm{O}_{2}$ in determining the rates of various processes. Heterogenous peroxide decomposition was found on this surface. Hydrogen peroxide was found as an intermediate in oxygen reduction on copper $(112,113)$. Vazquez et al. (114) showed that $\mathrm{H}_{2} \mathrm{O}_{2}$ can be reduced by the $\mathrm{Cu}(1)$ oxidized surface. The reduction was catalyzed by a redox cycle involving the $\mathrm{Cu}(\mathrm{I}) / \mathrm{Cu}(\mathrm{II})$ couple.

Wroblowa and Qaderi (32) found a two- and four-electron reduction in the series 
mechanism on steel in alkaline solutions in two well separated potential regions. At passivated steel surfaces the only product was a $\mathrm{HO}_{2}^{-}$. The surface with a prepassive oxide supports a series mechanism; at potentials negative to RHE the reaction proceeds completely to $\mathrm{OH}$.

Pyrochlores are attractive because they can act as a bifunctional oxygen electrocatalyst which can reversibly or near reversibly catalyze both the reduction and generation of $\mathrm{O}_{2} . \mathrm{O}_{2}$ reduction was measured on stoichiometric lead ruthenate $\mathrm{Pb}_{2} \mathrm{Ru}_{2} \mathrm{O}_{7}$ as a model compound because of its relative simplicity. Goodenough et al. (115) reported the reaction order $-1 / 2$ with the Tafel slope of $-60 \mathrm{mV}$ in alkaline solutions, in agreement with the data of Prakash et al. (116). The latter authors pointed out that a four-electron reduction is not clearly established for this surface because of the restricted transport of peroxide from the porous structure of the pyrochlore electrode. The $\mathrm{Ru}_{2} \mathrm{O}_{6}$ framework can be protonated for $\mathrm{pH}<2$ which makes oxygen atoms labile enough to undergo exchange with $\mathrm{O}_{2}^{-}(112)$ in reactions such as with $\mathrm{Pb}^{2+}$ for $\mathrm{pH}>2$ viz.,

$$
\mathrm{Pb}^{2+} \mathrm{OH}^{-}+\left(\mathrm{O}_{2}^{-}\right) \mathrm{ads} \rightarrow \mathrm{Pb}^{2+} \mathrm{O}_{2}^{-}+\mathrm{OH}^{-}
$$

or with $\mathrm{Ru}^{3+}$ for $\mathrm{pH}<2$. Steps not involving charge transfer are consistent with the Tafel slope of $-60 \mathrm{mV}$. A complete understanding of both $\mathrm{O}_{2}$ reduction and generation on $\mathrm{Pb}$ pyrochlores will require examination of the role oxygens and of $\mathrm{Ru}$ cations in breaking the $\mathrm{O}-\mathrm{O}$ bond $(112,113)$.

\section{Transition-metal Macrocyclic Compleres}

These compounds represent an interesting class of $\mathrm{O}_{2}$ reduction catalysts because they can replace noble metals, but also because they provide models in which active centers - central metal cations - can be identified and their activity related to their properties (117). This topic has been reviewed on several occasions $(1,114,118)$. Some of the transition metal macrocycles have 
substantial activity for $\mathrm{O}_{2}$ reduction. Most of the studies focused on the role of the ligand type and degree of polymerization and the role of the central metal cation in determining the catalytic activity. The activity of phthalocyanine (Pc), tetraphenylporphirine (TPhP) and tetramethylphenylporphirine (TMPhP) of Co decreases in this sequence due to different ligand structures (1). There are several correlations of the activity of Pc's with the type of the central metal cation based on their redox properties which are treated by the so-called redox theory (119). According to the studies of Lever et al. (120), redox processes on the metal in Pc's are expected only for $\mathrm{Cr}, \mathrm{Mn}, \mathrm{Fe}$ and $\mathrm{Co}$. A four-electron reduction on Pt-Pc cannot be explained by the redox theory since there is no redox couple with this molecule. $M(\mathrm{II}) / \mathrm{M}(\mathrm{II})$, but also $\mathrm{M}(\mathrm{II}) / \mathrm{M}(\mathrm{I})$ couples are assumed to take part in the redox cycle to reduce $\mathrm{O}_{2}$. A four-electron reduction has been observed with $\mathrm{FePc}$ and $\mathrm{Mn}-\mathrm{Pc}$, while $\mathrm{Co}-\mathrm{Pc}$ supports a two-electron reduction. Some peroxide is produced at high current densities but no peroxide can be detected at lower polarizations. Volcano curves, rather than linear plots, are emerging as a reliable correlation (cf. ref. 114 and references therein). Fig.16 illustrates such a correlation for several different macrocycles. A maximum is found for metal chelates having intermediate $M($ II)/M(III) redox potentials (121). The ability of the metal center to bind an extra-planar ligand is the other property, besides the redox couple, which facilitates the activity of phthalocyanines. The heat of $\mathrm{O}_{2}$ adsorption on the metal center appears to be the origin of the correlation of the activity for $\mathrm{O}_{2}$ reduction (expressed as potential at constant current) with the redox potential.

Detailed Raman spectroscopy studies of adsorbed Fe-TSPc by Simic-Glavaski et al. demonstrated the potential dependence of the Pc-electrode-interaction and related the redox behavior of Pc to its catalytic properties (122) Studies by Mốsbauer spectroscopy by Scherson 
et al. (123) showed that $\mathrm{Fe}$ in iron-based phthalocyanines is in an octahedral complex with $\mathrm{OH}^{\circ}$ in an axial position.

The activity of macrocycles supporting a four-electron reduction is considerable but the stability is a problem. The Tafel slopes of $-35 \mathrm{mV}(-2 \mathrm{RT} / 3 \mathrm{~F})$ are observed at low current densities and $-120 \mathrm{mV}(-2 \mathrm{RT} / \mathrm{F})$ at high current densities. The mechanism proposed by Yeager and coworkers (124) at large current densities is:

$$
\begin{aligned}
& \mathrm{M}(\mathrm{III}) \mathrm{OH}+\mathrm{e}=\mathrm{M}(\mathrm{II})+. \mathrm{OH} \\
& \mathrm{M}(\mathrm{II})+\mathrm{O}_{2}=\mathrm{M}(\mathrm{III})+\mathrm{O}_{2}^{-} \text {(ads) } \\
& \mathrm{M}(\mathrm{III})+\mathrm{O}_{2}^{-} \text {(ads) }+\mathrm{e} \rightarrow \text { intermediates }
\end{aligned}
$$

The last step is rate determining and leads to the breaking of the $\mathrm{O}-\mathrm{O}$ bond. This mechanism is in agreement with several other reports (114).

A four-electron reduction can be achieved by adsorbed soluble tetrasulfonated FePc (121) which, based on spectroscopic data (125), forms dimeric adsorbed species with an $\mathrm{O}_{2}$ molecule interacting with two metal centers viz., TSPcFe - O - O - FeTSPc. Collman, Anson and coworkers (126) have obtained a four-electron reduction with face-to-face dicobalt porphyrin dimers. The Co - Co spacing was tailored to be right for formation of the Co - O - O - Co bridge which facilitates the bond breaking. Anson et al. $(127,128)$ most recently synthesized several other macrocycles for a four-electron reduction of $\mathrm{O}_{2}$. When a set of potential electron donors in the form of $\mathrm{Ru}(\mathrm{II})$ are attached to center of Co porphyrin by coordination to pendant ligand groups (Fig. 17 ), a four-electron reduction is achieved, although the Co porphyrin supports only a two-electron reduction. Three coordinated $\mathrm{Ru}\left(\mathrm{NH}_{3}\right)_{3}{ }^{2+}$ groups were sufficient to produce an electrocatalyst for the four-electron reduction (129). The back-bonding of d-electrons from $\mathrm{Ru}(\mathrm{II})$ 
centers to pyridine ligands onto the porphyrin ring, and ultimately to the cobalt(II) $-\mathrm{O}_{2}$ adduct in the transition state, is believed to be the essential factor for achieving the four-electron reduction (126). None of the ruthenated cobalt porphyrines is active for $\mathrm{H}_{2} \mathrm{O}_{2}$ reduction indicating that a direct four-electron reduction is operative.

Radyuchkina et al. (130) reported pronounced effects of the substrate on the activity of cobalt tetra (n-metoxyphenil) porpfyrin which could not be explained by the redox mechanism. An extensive study of the role of substrate and of heat treatment has been reported recently by Savy et al. (131) on a cobalt naphthalocyanine isomeric mixture $\operatorname{CoNPc}(1,2)$. A bilayer structure, with active and inactive sites which differed in their attachment to the surface groups, was derived from spectroscopic data.

\section{Electrolyte Effects}

The optimization of the electrolyte can speed up the kinetics for $\mathrm{O}_{2}$ reduction. There are several factors through which the electrolyte can influence the pathway and $\mathrm{O}_{2}$ reduction kinetics (10). The main factors are activity coefficients of the reactants, intermediates and the transition state, acidity, competition for surface sites with $\mathrm{O}_{2}$, and dielectric properties of the electrolyte side of the interface. Perfluoroacids have higher solubility of $\mathrm{O}_{2}$ and lower adsorbability than electrolytes with specifically adsorbed anions. They also decrease the effective dielectric constant adjacent to the electrode surface. This favors the adsorption of the relatively non-polar $\mathrm{O}_{2}$ molecule (59). The results in perfluorosulfonic, sulfonic, sulfonimid, and carboacids show lower polarization than in sulfuric or phosphoric acids, mainly because of lower adsorption on Pt. An alternative approach is to use a mixture of phosphoric with the strong acid $\left(\mathrm{CF}_{3} \mathrm{SO}_{3} \mathrm{H}\right)$ to decrease 
the adsorption of phosphate anions. At high concentration some of these acids wet Teflon which results in flooding of the gas-fed electrodes (10). Perfluorinated sulfonic acids are many orders of magnitude stronger Brōnsted acids than concentrated $\mathrm{H}_{3} \mathrm{PO}_{4}$. The observed differences in the reaction rates are much lower than expected, if the rate determining step in $\mathrm{O}_{2}$ reduction is first order with respect to the $\mathrm{H}^{+}$activity (59) (vide supra) .

The perfluorosulfonic acid cation exchange polymer (Nafion) and similar sulfonic acid ionomers (Dow 560) have been used as electrolytes in the proton exchange membrane $\mathrm{H}_{2} / \mathrm{O}_{2}$ fuel cells (for review, see e.g. ref. (132)). As with perflouoroacids, the low adsorption of these polymer electrolytes on $\mathrm{Pt}$ is the major factor which facilitates a high performance of these fuel cells.

\section{Temperature Dependence of the Transfer Coefficient for $\mathrm{O}_{2}$ Reduction}

Electrochemical kinetics predicts Tafel slopes to be directly proportional to temperature with the transfer coefficient, $\alpha$ (or $\beta$ for one electron reaction), a temperature-independent constant. For some reactions this is not observed. A notable example for such behavior is $\mathrm{O}_{2}$ reduction. The Tafel slope $b$ for this analysis can be written in terms of the standard free energy of activation as discussed by Conway (133),

$1 / \mathrm{b}=[\vartheta \operatorname{lni} / \vartheta \mathrm{E}]_{\mathrm{T}}=-\vartheta / \vartheta \mathrm{E}\left\{\left[\left(\Delta H_{\ddagger}\right)^{\circ}-\mathrm{T}\left(\Delta \mathrm{S}_{\ddagger}\right)^{\circ}+\beta \mathrm{FE}\right] / \mathrm{RT}\right\}_{\mathrm{T}}$

where $\left(\Delta \mathrm{H}_{\mathfrak{f}}\right)^{\circ}$ and $\left(\Delta \mathrm{S}_{\mathfrak{f}}\right)^{\circ}$ are the standard enthalpy and standard entropy of activation. If $\left(\Delta \mathrm{H}_{\mathfrak{f}}\right)^{\circ}$ and $\beta$ are taken independent of potential, the eq. 30 becomes,

$[\text { Эlni } / \vartheta \mathrm{E}]_{\mathrm{T}}=-(\mathrm{a}+\mathrm{cT}) \mathrm{F} /(\mathrm{RT})$

with $a=9 / \vartheta \mathrm{E}\left\{\left[\left(\Delta \mathrm{H}_{\mathfrak{t}}\right)^{\circ}+\beta \mathrm{FE}\right] / \mathrm{RT}\right\}_{\mathrm{T}}$ and, $c=-\left[\vartheta\left(\Delta \mathrm{S}_{\mathfrak{f}}\right)^{\circ} / \mathrm{F} / \vartheta \mathrm{E}\right]_{\mathrm{T}}$ 
or

$$
\alpha=\mathbf{a}+\mathrm{cT} \text {, }
$$

where $\alpha$ is the apparent transfer coefficient.

The data on the temperature dependence of the transfer coefficient for $\mathrm{O}_{2}$ reduction from various sources are not in good agreement. Temperature dependent $(134,135)$ and independent (136) Tafel slopes were reported. It was suggested that some of these measurements may require reproduction in purified phosphoric acid solutions (4). Scharifker et al. (35) using microelctrodes found temperature dependent Tafel slopes and ascribed the opposite results to the impurity effects. In a thorough study of $\mathrm{O}_{2}$ reduction on $\mathrm{Pt}$ rotating disk electrode in phosphoric acid in the temperature range from 25 to $250^{\circ} \mathrm{C}$ and at potentials where no $\mathrm{PtOH}$ layer is formed, Clouser et al. (58) showed essentially no temperature dependence of the Tafel slope. The apparent transfer coefficient was found linearly related to temperature with the value 0.5 at $25^{\circ} \mathrm{C}, \alpha=$ $a+c T$, with $a=0.08$ and $c=0.0014 \mathrm{~K}^{-1}$ (Fig. 18). The large part of the potential dependence of the reaction rate is apparently associated with the entropy of activation rather than the change of height of the potential energy barrier (137). On the other hand, the $\mathrm{O}_{2}$ reduction rate depends on temperature at constant overpotential and the overpotential is expected to affect the barrier in the normal way.

The understanding of the anomalous temperature dependence of the Tafel slope is not satisfactory. There are several factors which can contribute to temperature dependence of $\beta$ which include potential dependent adsorption of the solution phase species, restructuring of the solution in the compact double layer, proton and electron tunnelling, changes in symmetry of the potential energy barrier, and impurity effects (134). Damjanovic (138) showed that by separating 
temperature- dependent and temperature-independent terms in $\Delta H_{q}$ and $\Delta S_{q}$, the effective temperature-independent enthalpy and effective temperature-dependent entropy of activation could be defined and formally the temperature dependence of $\beta$ can be accounted for. In particular, the $\beta$ value of 0.5 at $25^{\circ} \mathrm{C}$ requires explanation. One possibility is that the $\mathrm{O}_{2}$ reduction is controlled by adsorption of neutral $\mathrm{O}_{2}$ molecule. In that case the potential dependence may be associated principally with an entropy of activation and its dependence on the potential gradient across the interface (58).

\section{Concluding Remarks}

Given its importance, the complexity of its mechanism and its very slow kinetics, $\mathrm{O}_{2}$ reduction will continue to be in the focus of electrochemical research in years ahead. The lack of agreement on the reaction mechanism on $\mathrm{Pt}$, which may look disappointing after years of the activity in this field, should not distract further efforts. It will probably be resolved with a more broad approach to the problem which would encompass the behavior of $\mathrm{PtOH}$, anions and water at the electrode surface. The urgent need is to improve catalytic activity of $\mathrm{Pt}$ and synthesize new, possibly non-noble metal catalysts. New experimental techniques are available to obtain new level of information necessary for further advance in the field. Particularly promising are various in situ spectroscopies and scanning probes, some of them requiring synchrotron radiation. Several of these techniques provide information on the reaction and surface properties under operating conditions which was not at hand a few years ago. 
Acknowledgements

The author thanks J. Johnson for helpful comments. This work was performed under the auspices of the US Department of Energy, Division of Chemical Sciences, Office of Basic Energy Sciences under Contract No. DE-AC02-76CH00016. 


\section{Figure Captions}

Fig.1 Models for $\mathrm{O}_{2}$ adsorbed on metal sites. Adapted from ref. 1.

Fig. 2 Charge associated with adsorbed intermediate(s) in $\mathrm{O}_{2}$ reduction on $\mathrm{Au}$ in $0.1 \mathrm{M}$ $\mathrm{KOH}$ as a function of potential. See eq. 9.(Reproduced from ref. 34 with permission).

Fig. 3 General scheme of $\mathrm{O}_{2}$ reduction. (Reproduced from ref. 33 with permission).

Fig. $4 I_{\mathrm{D}} / I_{\mathrm{R}}$ vs. $\omega^{-1 / 2}$ for $\mathrm{O}_{2}$ reduction on $\mathrm{Pt}$ in $85 \% \mathrm{H}_{3} \mathrm{PO}_{4}$ at $298 \mathrm{~K}$ at various disk potential. Ring potential $E_{\mathrm{H}}=1.2 \mathrm{~V}, N=0.40$. Insert: $\mathrm{J}-\mathrm{S}$ plot obtained from this data (cf. eqs. 12 and 13). (Reproduced from ref. 1 with permission).

Fig. 5 iR-corrected Tafel plots for $\mathrm{O}_{2}$ reduction in proton exchange membrane fuel cell at 368K and 5atm pressure for $\mathrm{Pt}$ and $\mathrm{Pt}$ alloy electrocatalysts. $\mathrm{Pt}$ loading is $0.3 \mathrm{mg} / \mathrm{cm}^{2}$. Pt/Co, ETEK (0); Pt/Co, JMRC (1); Pt/Ni ETEK, (D); Pt/Ni JMRC

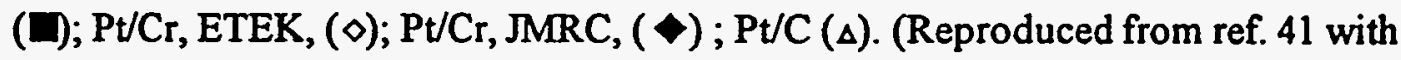
permission).

Fig. $6 \mathrm{O}_{2}$ reduction on the low-index planes of $\mathrm{Au}$ in $0.1 \mathrm{M} \mathrm{NaOH}$. Sweep rate $50 \mathrm{mV} / \mathrm{s}$; rotation rate $1600 \mathrm{rpm}$. (Reproduced from ref. 76 with permission).

Fig. 7 Disk and ring currents during $\mathrm{O}_{2}$ reduction on Au single crystal electrodes in $0.1 \mathrm{M}$ $\mathrm{NaOH}$ solution. $E_{\mathrm{R}}=0.3 \mathrm{~V} ; 50 \mathrm{mV} / \mathrm{s}$; Disc area $0.195 \mathrm{~cm}^{2} ; \mathrm{N}=0.20$.(a) 400 , (b) 625 , (c) 900 , (d) 1225 , (e) 1600 , (f) $2025 \mathrm{rpm}$. (Reproduced from ref. 80 with permission).

Fig. 8 Correlation between the calculated normalized surface energy, $\gamma(h k l) / \gamma(210)$, and 
the heterogenous rate constant, $\log k(h k l)$, for $E=160 \mathrm{mV}$. (Reproduced from ref. 87 with permission).

Fig. 9 Disk currents during $\mathrm{O}_{2}$ reduction on $\mathrm{Pt}$ single crystal electrodes in $0.1 \mathrm{M} \mathrm{HClO}_{4}$ solution. $50 \mathrm{mV} / \mathrm{s} ; 900 \mathrm{rpm}$. Insert: Tafel plots at $900 \mathrm{rpm}$. (Reproduced from ref. 27 with permission). Potential scale vs. SCE.

Fig. 10 Disk and ring currents during $\mathrm{O}_{2}$ reduction on $\mathrm{Pt}$ single crystal electrodes in $0.05 \mathrm{M} \mathrm{H}_{2} \mathrm{SO}_{4}$ solution. $E_{\mathrm{R}}=0.95 \mathrm{~V}(\mathrm{SCE}) ; 50 \mathrm{mV} / \mathrm{s} ; 1600 \mathrm{rpm}$. Insert: Tafel plots at 900rpm. (Reproduced from ref. 28 with permission).

Fig. 11 Disk and ring currents during $\mathrm{O}_{2}$ reduction on rotating $\mathrm{Pt}(111)$ in $0.05 \mathrm{M} \mathrm{H}_{2} \mathrm{SO}_{4}$ solution. $E_{\mathrm{R}}=0.95 \mathrm{~V}(\mathrm{SCE}) ; 50 \mathrm{mV} / \mathrm{s}$. (a) voltammetry of $\mathrm{Pt}(111)$ in the rotating ring-disk assembly without $\mathrm{O}_{2}$ and rotation. (b) Tafel plot at $900 \mathrm{rpm}$. (c) Levich plot at various electrode potentials. (Reproduced from ref. 28 with permission).

Fig. 12 Real space model of the aligned hexagonal $\mathrm{Tl}$ phase conducive to a four-electron reduction of $\mathrm{O}_{2}$ on $\mathrm{Au}(111)$ in $0.1 \mathrm{M} \mathrm{NaOH}$ solution at $-0.3 \mathrm{~V}$. (Reproduced from ref. 97 with permission).

Fig. 13 (a) Radial scans though one of the low-order diffraction peaks of the Tl monolayer on $\mathrm{Au}(111)$ in $0.1 \mathrm{M} \mathrm{HClO}_{4}$ with $5 \mathrm{mM} \mathrm{Tl}+$ in the rotated-hexagonal phase. (b) Same measurements as in (a) but in the presence of $\mathrm{O}_{2}$ reduction. (Reproduced from ref. 39 . with permission).

Fig. 14 Steady-state measurements of $\mathrm{O}_{2}$ reduction on $\mathrm{Pt}(111)$ in $0.05 \mathrm{M} \mathrm{H}_{2} \mathrm{SO}_{4}$ in the presence (...) and absence (ooo) of $5 \mathrm{mM} \mathrm{CuSO}_{4} ; 200 \mathrm{rpm}$. Insert: UPD of Cu in the same solution without $\mathrm{O}_{2}$; sweep rate $5 \mathrm{mV} / \mathrm{s}$. (Reproduced from ref. 101 
with permission).

Fig. 15 Disk and ring currents during $\mathrm{O}_{2}$ reduction on rotating $\mathrm{Pt}$ electrode in $0.2 \mathrm{M} \mathrm{HClO}$, solution (---) in the absence, and (-) presence of $0.02 \mathrm{mM} \mathrm{Pb}^{2+} . E_{\mathrm{R}}=0.95 \mathrm{~V}$; $40 \mathrm{mV} / \mathrm{s}$. (Reproduced from ref. 66 with permission).

Fig. 16 Volcano plot for $\mathrm{O}_{2}$ reduction in $0.1 \mathrm{M} \mathrm{NaOH}$ on different macrocycles on graphite electrode. Potentials at $i=50 \mu \mathrm{A} / \mathrm{cm}^{2}$ vs. the $\mathrm{M}(\mathrm{II} / \mathrm{III})$ redox potential (vs. SCE) of the macrocycle. (Reproduced from ref. 121 with permission).

Fig. 17 Molecular structures of cobalt porphyrines to which complexes of Ru(II) are appended by coordination to pendant ligand groups on the porphyrin rings. (Reproduced from ref. 128 with permission).

Fig. 18 Plot of apparent transfer coefficient vs. temperature for $\mathrm{O}_{2}$ reduction in $\mathrm{H}_{3} \mathrm{PO}_{4}$. (Reproduced from ref. 59 with permission). 


\section{References}

1. M.R. Tarasevich, A. Sadkowski, E. Yeager, in Comprehensive Treatise of Electrochemistry, vol. 7, B. Conway, J.O'.M. Bockris, E. Yeager, S. U. M. Khan, R. E. White Eds., (Plenum Press, New York, 1983), p. 301.

2. D.E.J. Schiffrin in, Electrochemistry, Specialist Periodical Report, vol.8, D. Pletcher Ed., (Royal Society of Chemistry, London, 1983), p 126.

3. K. Kinoshita, Electrochemical Oxygen Technology. (J. Wiley and Sons, Inc., New York, 1990).

4. A.J. Appleby, J. Electroanal. Chem. 357, 117 (1993) .

5. A. Damjanovic, in Electrochemistry in Transition. O.J. Murphy, S. Srinivasan, Eds., (Plenum Press, New York, 1992), p. 107.

6. E.B. Yeager, Electrochim. Acta 29, 1527 (1984).

7. Yu.V. Pleskov, V. Yu. Filinovskii, The Rotating Disk Electrode (Consultants Bureau, New York !976).

8. J.S. Valente, Chem. Revs., 73 (1973) 235.

9. J. Zagal, Coord. Chem. Rev., 119 (1992) 89.

10. Yeager, M. Razaq, D. Gervasio, A. Razaq, D. Tryk, in Structural Effects in Electrocatalysis and Oxygen Electrochemistry, D. Scherson, D. Tryk, M. Daroux, X. Xing Eds., (The Electrochem. Soc. Inc. Pennington, 1992), Proc. vol. 92-11, p. 440.

11. D.B. Sepa, M.V. Vojnovic, A. Damjanovic, Electrochim. Acta 26, 781 (1981) .

12. H. Steininger, S. Lehwald, H. Ibach, Surf. Sci. 123, 1 (1982).

13. D.A.Outka, J. Stohr, W. Jark, P. Stevens, J. Solomon, R.J. Madix, Phys. Rev. B 35, 4119 (1987).

14. T. Engel and G. Ertl, in Advances in Catalysis, Vol. 28, D.D. Eley, H. Pines, P. B. Weisz, Eds., (Academic Press, New York) 1979.

15. C.Puglia, A. Nilsson, B. Hernnais, O. Karis, P. Bennich, N. Martensson, Surf. Sci. 342, 119 (1995).

16. J. Schidt, Ch. Stuhlmann, H. Ibach, Surf. Sci. 284, 121 (1993). 
17. N. Freyer, M. Kiskinova, G. Pirug, H.P. Bonzel, Surf. Sci. 166, 206 (1986).

18. G.N. Derry , P. N. Ross, J. Phys. Chem. 82, 2772 (1985).

19. A. Raukema, D.A. Butler, F.M.A. Box, A.W. Kleyn, Surf. Sci. 347, 151 (1996) .

20. H. Albers, W.J. van der Wal, G. A. Bootsma, Surf. Sci. 68, 47 (1977).

21. R.B. Grant , R.M. Lambert, Surf. Sci. 146, 256 (1984).

22. M.A. Chester, G. A. Somorjai, Surf. Sci. 52, 21 (1975) .

23. R. R. Adzic, N.M. Markovic, V.B. Vesovic, J. Electroanal. Chem. 165, 105 (1984).

24. M. Alvarez-Rizatti, K. Juttner, J. Electroanal. Chem. 144, 351(1982)

25. S.Strbac, N.A. Anastasijevic, R.R. Adzic, J.Electroanal. Chem. 240, 239 (1988); 323, 179 (1992)

26. see e.g., R.R. Adzic, in Modern Aspects of Electrochemistry, R. E. White, B. Conway and J.O'.M. Bockris, Eds., (Plenum Press, New York, 1990), p. 163.

27. N.M. Markovic, R. R. Adzic, B.D. Cahan, E.B. Yeager, J. Electroanal. Chem. 377, 249 (1994).

N.M. Markovic, R. R. Adzic, B.D. Cahan, E.B. Yeager, ISE Proceedings, Montreaux, 1991; p.138.

28. N.M. Markovic, H. Geistager, P.M. Ross, J. Phys. Chem., 99, 3411 (1995).

29. B.D. Cahan, M. Villulas, J. Electroanal. Chem. 307, 263 (1991).

30. Yu.V. Pleskov, V.Yu. Filinovskii, The Rotating Disk. Electrode, Consultants Bureau, New York, 1976.

31. V.B. Vesovic, N. A. Anastasijevic, R.R. Adzic, J. Electroanal. Chem. 218, 53 (1987)

32. H.S. Wroblowa, S.B. Qaderi, J. Electroanal. Chem. 279, 231 (1990).

33. N. A. Anastasijevic, V.B. Vesovic, R.R. Adzic, J. Electroanal. Chem. 229, 305 (1987) ; 229, 317 (1987).

34. B-1. Wu, H-w. Lei, Ch-s. Cha, J.Electroanal. Chem. 377, 227 (1994).

35. B. R. Scharifker, P. Zelenay, J.O'M. Bockris, J. Electrochem. Soc. 134, 2714 (1987).

36. D. Pletcher, S. Sotiropoulos, J. Electroanal. Chem., 356, 109 (1993) . 
37. C-h. Chen, N. Washburn, A.A. Gewirth, J. Phys. Chem. 97, 9754 (1993).

38. W. Polewska, C.M. Vitus, B.M. Ocko, R.R. Adzic, J. Electroanal. Chem. 364, 265 (1994).

39. R.R. Adzic, J. Wang, B.M. Ocko, Electrochim. Acta 40, 83 (1994).

40. K.I. Pandya, W.E. O'Grady, D.A. Corrigan, J. McBreen, R.W. Hoffman, J. Phys. Chem. 137, 383 (190).

41. S. Mukerjee, S. Srinivasan, M. Soriaga, J. Mc Breen, J. Phys. Chem. 99, 4577 (1995).

42. A. Damjanovic, M.A. Genshaw, J.O'M. Bockris, J. Phys. Chem., 45, 4057 (1964).

43. M.R. Tarasevich, Electrokhimiya, 4, 210 (1968).

44. R.W. Zurilla, E.B. Yeager, Technical Report No. 23, Case Western Reserve University, 1969.

45. V.S. Bagotskii, M.R. Tarasevich, V.Yu. Filinovskii, Electrokhimiya, 5, 1216 (1969).

46. K.L. Hsueh, D.T. Chin, S. Srinivasan, J. Electroanal. Chem. 153 (1983) 79.

47. H.S. Wroblowa, Yen-Chi-Pan, G. Razumney, J. Electroanal. Chem. 69, 195 (1976).

48. V.S. Bagotskii, M.R. Tarasevich, V.Yu. Filinovskii, Elektrokhimiya 5, 1218 (1969); V.S. Bagotskii, M.R. Tarasevich, V.Yu. Filinovskii, Elektrokhimiya, 8, 84 (1972).

49. S. Strbac, R.R. Adzic, J. Serb. Chem. Soc. 57, 835 (1992)

50. W.E. O'Gady, E.J. Taylor, S. Srinivasan, J.Electroanal. Chem. 132 (1982) 137.

51. R.R. Adzic, in Electrocatalysis, W.E. O'Grady, P.N. Ross, F.G. Will, Eds., Proc. Symp. (The Electrochem. Soc. Inc., Princeton, 1982), p.309.

52. A. Damjanovic, V. Brusic, J.O'M. Bockris, J. Phys. Chem. 71, 2471 (1967) .

53. D.B. Sepa, M.V. Vojnovic, Lj.M. Vracar, A. Damjanovic, Electrochim. Acta 32, 129 (1987).

54. M.R. Tarasevich, V.S. Vilinskaya, Elektrokhimiya 9, 96 (1973).

55. R.R. Adzic, in Structural Effects in Electrocatalysis and Oxygen Electrochemistry, D. Scherson, D. Tryk, M. Daroux, X. Xing Eds., (The Electrochem. Soc. Inc. Pennington, 1992), Proc. vol. 92-11, p. 419. 
56. F.A. Uribe, M.S. Wilson, T.E. Springer, S. Gottesfeld, in Structural Effects in Electrocatalysis and Oxygen Electrochemistry, D. Scherson, D. Tryk, M. Daroux, X. Xing Eds., (The Electrochem. Soc. Inc. Pennington, 1992), Proc. vol. 92-11, p. 494.

57. P.W. Faguy, N.M. Markovic, R.R. Adzic, C.A. Fierro, E.B. Yeager, J. Electroanal. Chem. 289, 245 (1990); P.W. Faguy, N.S. Marinkovic, R.R. Adzic, Langmuir 12, 243 (1996).

58. P.W. Faguy, N.M. Markovic, P.N. Ross Jr., J. Electrochem. Soc. 140, 1638 (1993).

59. S.J. Clouser, J.C. Huang, E. Yeager, J. Appl. Electrochem. 23, 597 (2993).

60. E. Yeager, M. Razaq, D. Gervasio, A. Razaq, D. Tryk, J. Serb. Chem. Soc. 57, 819 (1992).

61. A.B. Anderson, in Structural Effects in Electrocatalysis and Oxygen Electrochemistry, D. Scherson, D. Tryk, M. Daroux, X. Xing Eds., (The Electrochem. Soc. Inc. Pennington, 1992), Proc. vol. 92-11, p.434.

62. A.B. Anderson, E. Grantscharova, S. Seong, in "Oxygen Electrochemistry", R.R. Adzic, F.C. Anson, K.Kinoshita Eds., The Elctrochem. Soc. Inc. Pennington, 1996), Proc. vol. 95-26, p.1.

63. K.A. Radyushkina, O.E. Zonina, M.R. Tarasevich, Electrokhimiya, 28, 906 (1992).

64. R.R. Adzic, M. Spasojevic, A. R. Despic, Electrochim. Acta, 24, 569 (1979).

65. N. Markovic, E.Yeager, R.R. Adzic, ESM Extended Abstracts, 85-1, 919 (1985).

66. S.A.S. Machado, A.A. Tanaka, E.R. Gonzales, Electrochim. Acta 39, 2591 (1994).

67. J.A. Appleby, in Comprehensive Treatise of Electrochemistry, vol. 7, B. Conway, J.O'.M. Bockris, E. Yeager, S. U. M. Khan, R. E. White Eds., (Plenum Press, New York, 1983), p. 173.

68. V.M. Jalan, E. J. Taylor, J. Electrochem. Soc., 130, 2299 (1983).

69. J.T. Glass, G.L. Cahen, G.E. Stoner, J. Electrochem. Soc. 134, 58 (1987).

70. S. Mukerjee, J. Appl. Electrochem. 20, 537 (1990).

71. M.R. Tarasevich, Elektrokhimiya, 9, 599 (1973).

72. M. Appel, A.J. Appleby, C.R. Acad. Sci. Paris, Ser. C 280, 208 (1975).

73. R.W. Zurilla, R.K. Sen, E.B.Yeager, J. Electrochem. Soc. 125, 1103 (1978). 
74. S.I Androuseva, M.R. Tarasevich, K.A. Radyushkina, Elektrokhimiya 13, 253 (1977).

75. J. Clavilier, J. Electroanal. Chem. 107, 211 (1980).

76. R.R. Adzic, N.M. Markovic, J. Electroanal. Chem. 138, 443 (1982);

R. R. Adzic, N.M. Markovic, V.B. Vesovic, J. Electroanal. Chem. 165, 105 (1984);

N.M. Markovic, R. R. Adzic,V.B. Vesovic, J. Electroanal. Chem. 165, 123 (1984).

77. N.A. Anastasijevic, S. Strbac, R.R. Adzic, J. Electroanal. Chem. 240, 239 (1988).

78. J.D.E. McIntyre, W.F. Peck, in The Physics and Chemistry of Electrocatalysis, J.D.E. McIntyre, M.J. Weaver, E. Yeager, Eds., (The Electrochemical Society, Pennigton, NJ, 1984) p 102.

79. E. Taylor, N.R.K. Vilambi, A. Gelb, J. Electrochem. Soc. 136, 1939 (1989).

80. : - S. Strbac, N.A. Anastasijevic, R.R. Adzic, J. Electroanal. Chem. 323, 179 (1992).

81. S.Strbac, R.R. Adzic, J. Electroanal. Chem. in press.

82. P. Fischer, J. Heitbaum, J. Electroanal. Chem. 112, 231 (1980).

83. D.M. Kolb, in "Structure of Electrified Interfaces", J. Lipkowski and P.N. Ross, Eds., VCH Publishers, Inc., New York (1993), p. 65.

84. W. Polewska, C.M. Vitus, B.M. Ocko, R.R. Adzic, J. Electroanal. Chem. 364, 265 (1994)

85. N.M. Markovic, I.M. Tidswell, P.N Ross, Langmuir 10, 1 (1994).

86. S. Strbac, R.R. Adzic, J. Serb. Chem. Soc. 57, 835 (1992).

87. R.R. Adzic, S. Strbac, N. Anastasijevic, Mat. Chem. Phys. 22, 349 (1989).

88. A. Zwetanova, K. Juttner, J. Electroanal. Chem. 119, 149 (1981).

89. M. Isakovic, R. Adzic, unpublished.

90. P.Ross, J. Electrochem. Soc. 20, 78 (1970).

91. A. Tanaka, K. Kanamura, R. Adzic, B. Cahan, E. Yeager, Proc. Electrochem. Soc. Meeting 90-1, Montreal, 1990, p.969.

92. F. El Kadiri, R. Faure, R. Durand, J. Electroanal. Chem. 301, 177 (1991). 
93. R. Durand, R. Faure, F. Gloaguen, D. Aberdan, in "Oxygen Electrochemistry", R.R. Adzic, F.C. Anson, K.Kinoshita Eds., The Electrochem. Soc. Inc. Pennington, (1996), vol. $95-26$ p.27.

94. H. Kita, H-W. Lei, Y. Gao, J. Electroanal. Chem. 379, 407 (1994).

95. R.R. Adzic, in "Advances in Electrochemistry and Electrochemical Engineering" vol. 13, H. Gerischer, C. Tobias, Eds., J.Wiley, New York (1984), p. 159.

96. G. Kokkinidis, J. Electroanal. Chem. 201, 217 (1986)

97. R.R. Adzic, J. X. Wang, in "Oxygen Electrochemistry", R.R. Adzic, F.C. Anson, K.Kinoshita Eds., The Electrochem. Soc. Inc. Pennington, (1996), vol. 95-26 p.61.

98. C-h. Chen, A.A. Gewirth, J. Amer. Chem. Soc., 114, 5439 (1992).

99. T. Abe, Y. Miki, K. Itaya, Bul. Chem. Soc. Jpn. 67, 2075 (1994).

100. M.F. Toney, J.N. Howard, J. Richer, G.L. Borges, J.G. Gordon, O.R. Melroy, Phys. Rev. Lett. 75, 4472 (1995).

101. T. Abe, G.M. Swain, K. Sahsikata K. Itaya, J. Electroanal. Chem. 382, 73 (1995).

102. Z. Shi, J. Lipkowski, J. Electroanal. Chem. 364, 289 (1994).

103. N. Markovic, E. Yeager, R. Adzic, Electrochem. Soc. Meeting Ext. Abstr., 85-1, 919 (1985).

104. R.R. Adzic, J. Wang, C.M. Vitus, B.M. Ocko, Surf. Sci. 293, L876 (1993).

105. N Anastasijevic, Z.M. Dimirtijevic, R.R. Adzic, Electrochim. Acta 37, 457 (1992).

106. V. Jovancicevic, J.O'M. Bockris, J. Electrochem. Soc. 133, 1797 (1986).

107. S. Zecevic, D.M. Drazic, S. Gojkovic, J. Electroanal. Chem. 265, 179 (1989).

108. V.A. Presnov, A.M. Trunov, Sov. Electrochem. 11, 60 (1975).

109. E.J. Calvo, D.J. Schriffin, J. Electroanal. Chem. 163, 257 (1984);

E.J. Calvo, D.J. Schriffin, J. Electroanal. Chem. 243, 171 (1988).

110. S. Zecevic, D.M. Drazic, S. Gojkovic, Electrochim. Acta 39, 975(1994).

S. Zecevic, D.M. Drazic, S. Gojkovic, Electrochim. Acta 36, 5 (1991).

111. E.R. Vago, E.J. Calvo, J.Chem. Soc. Faraday Trans. 91, 2323 (1995);

E.R. Vago, E.J. Calvo, J. Electroanal. Chem. 388, 161 (1995). 
112. K. Balakrishnan, V.K. Venkatisan, Electrochim. Acta 24, 131 (1979).

113. A.I. Molodov, Elektrokhimiya 18, 1186 (1981).

114. M.V. Vazquez, S.R. de Sanchez, E.J. Calvo, D.J. Schiffrin, J. Electroanal. Chem. 374, 179 (1994)

115. J.B. Goodenough, R. Manoharan, M. Paranthamn, J. Amer. Chem. Soc. 112, 2076 (1990).

116. J.Prakash, D.Tryk, W. Aldred, E. Yeager, in Electrochemistry in Transition. O.J. Murphy, S. Srinivasan, Eds., (Plenum Press, New York, 1992), p. 93.

117. J. Zagal, Coord. Chem. Rev. 119, 89 (1992)

118. M.R. Tarasevich, K.A. Radyushkina, Russ. Chem. Rev. 49, 718 (1980).

119. J.P. Randin, Electrochim. Acta 19, 83 (1974)

120. A.B.P. Lever, P.C. Minor, Inorg. Chem. 20, 4015 (1980).

121. J. Zagal, M.J. Aguirre, L. Basez, J. Pavez, in "Oxygen Electrochemistry", R.R. Adzic, F.C. Anson, K.Kinoshita Eds., The Elctrochem. Soc. Inc. Pennington, 1996), vol. 9526 p.74.

122. B. Simic-Glavaski, S. Zecevic, E. Yeager, J. Amer. Chem. Soc. 107, 5625 (1985). B. Simic-Glavaski, in Phthalocianines 3, C.C. Leznoff, A.B.P. Lever, Eds. ,(VCH Publishers, Inc. 1993), p. 119.

123. D. Scherson, S. B. Yao, E.B. Yeager, J. Eldridge, M. K. Kordesh, R.W. Hoffman, J. Phys. Chem. 87, 932 (1983).

124. J. Zagal, P. Bindra, E. Yeager, J. Electrochem. Soc. 127, 1506 (1980).

125. B.Z. Nikolic, R. R. Adzic, E.B. Yeager, J. Electroanal. Chem. 103, 281 (1979).

126. J.P. Collman, P. Denisevich, Y. Konai, M. Marroco, C. Koval, F.C. Anson, J. Amer. Chem. Soc. 102, 6027 (1980).

127. C. Shi, F.C. Anson, J. Amer. Chem. Soc. 113, 9564 (1991);

C. Shi, F.C. Anson, Inorg. Chem., 31, 5078 (1992).

128. Y. Lei, F.C. Anson, Inorgan. Chem. 33, 5003 (1994);

C.Shi, K.W. Mak, K.S. Chan, F.C. Anson, J. Electroanal. Chem. 397, 321 (1995).

129. B. Steiger, C. Shi, F.C. Anson, Inorg. Chem., 32, 2107 (1993). 
130. K.A. Radyushkina, M.R. Tarasevich, O.A. Levina, Russ. Electrochem. 30, 586 (1994).

131. A.Biloul, O. Contamin, G. Scarbeck, M. Savy, B. Palys, J. Riga, J. Verbist, J. Electroanal. Chem. 365, 239 (1994).

132. S. Srinivasan, O.A. Velev, A. Parthasarathy, D. Manko, A.J. Appleby, J. Power Sources 36, 299 (1991).

133. B.E. Conway, in "Modern Aspects of Electrochemistry" vol. 16, B.E. Conway, J.O'M. Bockris, R. White, Eds.(Plenum, New York, 1986) p.103.

134. A.J. Appleby, J. Electrochem. Soc. 117, 328 (1970) ; 117, 641 (1970) .

135. M.A. Enayetullah, T.D. DeVibiss, J.O'M. Bockris, J. Electrochem. Soc. 136, 3369 (1989).

136. A.J. Appleby, J. Electrochem. Soc. 117, 1157 (1970).

137. B.E. Conway, D.F. Tessier, D.P. Wilkinson, J. Electroanal. Chem. 199, 249 (1986).

138. A. Damjanovic, J. Electroanal. Chem., 355, 57 (1993). 
TABLE 1: Comparison of Activation Energy for Oxygen Reduction with Results from the In-Situ EXAFS and XANES Analysis on Pt and Pt Alloy Electrocatalysts at 0.54 and $0.84 \mathrm{~V}$ vs $\mathrm{RHE}^{a}$

\begin{tabular}{|c|c|c|c|c|c|c|c|c|c|c|c|c|c|c|c|}
\hline \multirow[b]{3}{*}{ elećtrocatalyst } & \multirow[b]{3}{*}{$\Delta H_{2 \mathrm{al}}(\mathrm{kJ} / \mathrm{mol})$} & \multicolumn{7}{|c|}{$0.54 \mathrm{~V}$ vs $\mathrm{RHE}$} & \multicolumn{7}{|c|}{$0.84 \mathrm{~V}$ vs RHE } \\
\hline & & \multirow[b]{2}{*}{$\left(h_{J}\right)_{t, s}$} & \multicolumn{2}{|c|}{$\mathrm{Pt}_{\mathrm{t}}-\mathrm{Pt}_{\mathrm{t}}$} & \multicolumn{2}{|c|}{$\mathrm{Pt}-\mathrm{M}$} & \multirow[b]{2}{*}{$M-M(\AA)$} & \multirow[b]{2}{*}{$M-\operatorname{Pr}(\AA)$} & \multirow[b]{2}{*}{$\left(h_{3}\right)_{\text {Ls }}$} & \multicolumn{2}{|c|}{$\mathrm{Pt}_{\mathbf{t}}-\mathrm{Pt}$} & \multicolumn{2}{|c|}{$\mathrm{Pt}-\mathrm{M}$} & \multirow[b]{2}{*}{$M-M(\AA)$} & \multirow[b]{2}{*}{$M-\operatorname{Pt}(\AA)$} \\
\hline & & & $(\dot{A})$ & $N$ & $(\AA)$ & $N$ & & & & $(\AA)$ & $N$ & $(\dot{A})$ & $N$ & & \\
\hline $\begin{array}{l}\text { PU/C } \\
\text { PUCr (ETEK) } \\
\text { PUCr (JMRC) } \\
\text { PtCo (ETEK) } \\
\text { PtCo (JMRC) } \\
\text { PUNi (ETEK) } \\
\text { PUNi (JMRC) }\end{array}$ & $\begin{array}{l}62.17 \\
28.72 \\
27.63 \\
23.74 \\
35.44 \\
23.84 \\
42.23\end{array}$ & $\begin{array}{l}0.329 \\
0.360 \\
0.360 \\
0.368 \\
0.401 \\
0.375 \\
0.409\end{array}$ & $\begin{array}{l}2.77 \\
2.70 \\
2.71 \\
2.71 \\
2.68 \\
2.71 \\
2.68\end{array}$ & $\begin{array}{l}8.7 \\
7.2 \\
8.5 \\
6.5 \\
6.9 \\
7.8 \\
9.1\end{array}$ & $\begin{array}{l}2.67 \\
2.69 \\
2.64 \\
2.63 \\
2.66 \\
2.61\end{array}$ & $\begin{array}{l}3.1 \\
2.8 \\
2.3 \\
2.5 \\
2.4 \\
2.7\end{array}$ & $\begin{array}{l}2.65 \\
2.63 \\
2.55 \\
2.53\end{array}$ & $\begin{array}{l}2.64 \\
2.51 \\
2.64 \\
2.63\end{array}$ & $\begin{array}{l}0.370 \\
0.361 \\
0.358 \\
0.365 \\
0.390 \\
0.372 \\
0.404\end{array}$ & $\begin{array}{l}2.77 \\
2.71 \\
2.71 \\
2.69 \\
2.68 \\
2.71 \\
2.68\end{array}$ & $\begin{array}{l}6.8 \\
7.0 \\
8.8 \\
5.9 \\
7.6 \\
7.6 \\
9.5\end{array}$ & $\begin{array}{l}2.67 \\
2.70 \\
2.64 \\
2.63 \\
2.65 \\
2.57\end{array}$ & $\begin{array}{l}3.2 \\
2.9 \\
2.9 \\
2.3 \\
2.3 \\
3.3\end{array}$ & $\begin{array}{l}2.67 \\
2.64 \\
2.57 \\
2.53\end{array}$ & $\begin{array}{l}2.64 \\
2.50 \\
2.66 \\
2.63\end{array}$ \\
\hline
\end{tabular}

${ }^{\circ}\left(h_{j}\right)_{t, s}$ Pr d-orbital vacancy per atom. $N$, coordination number. ${ }^{b}$ At $0.84 \mathrm{~V}$, the $\mathrm{Pt}-0$ values were $N=1.69$ and $R=2.04 \AA$.

(Reproduced from ref. 41 with permission). 
Table 2

Some kinetic parameters for $\mathrm{O}_{2}$ reduction on low index plane rotating single-crystal platinum electrodes in $0.1 \mathrm{M} \mathrm{HClO}$ at $22^{\circ} \mathrm{C}$

\begin{tabular}{|c|c|c|c|c|c|c|c|c|}
\hline$(h k l)$ & $n$ & 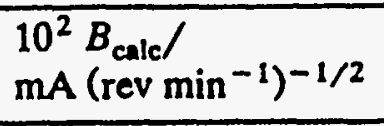 & $\begin{array}{l}10^{2} B_{\exp } / \\
\mathrm{mA}\left(\text { rev min }^{-1}\right)^{-1 / 2}\end{array}$ & $E_{1 / 2} / V$ & $\begin{array}{l}\left(\partial_{E} / \partial_{\log i}\right)^{2} / \\
m V \text { decade }\end{array}$ & $\begin{array}{l}10^{2} k_{(111)} \\
\mathrm{cm} \mathrm{s}^{-1}\end{array}$ & $\begin{array}{l}10^{2} k_{(100) /} \\
\mathrm{cm} \mathrm{s}^{-1}\end{array}$ & $\begin{array}{l}10^{2} k_{(100)} / \\
\mathrm{cm} \mathrm{s}^{-1}\end{array}$ \\
\hline (111) & 4 & 4.3 & 4.32 & 0.525 & $\begin{array}{l}\text { Icd ca. } 60 \\
\text { hed ca. } 120\end{array}$ & $\begin{array}{l}1.1(0.5 \mathrm{~V}) \\
1.9(0.475 \mathrm{~V}) \\
2.6(0.45 \mathrm{~V})\end{array}$ & & \\
\hline$(100)$ & 4 & 4.3 & 4.32 & 0.475 & $\begin{array}{l}\text { led ca. } 60 \\
\text { hed ca. } 120\end{array}$ & & $\begin{array}{l}0.64(0.5 \mathrm{~V}) \\
1.00(0.475 \mathrm{~V}) \\
1.38(0.45 \mathrm{~V})\end{array}$ & \\
\hline (110) & 4 & 4.3 & 4.32 & 0.55 & $\begin{array}{l}\text { led ca. } 60 \\
\text { hed ca. } 120\end{array}$ & & & $\begin{array}{l}1.2(0.5 \mathrm{~V}) \\
2.0(0.475 \mathrm{~V}) \\
2-8(0.45 \mathrm{~V})\end{array}$ \\
\hline
\end{tabular}

Ied and hed stand for low and high current densities; disk surface areas are $0.30 \mathrm{~cm}^{2}, 0.298 \mathrm{~cm}^{2}$ and $0.292 \mathrm{~cm}^{2}$ for $(100),(110)$ and $(111)$ electrodes respectively. (Reproduced from ref. 28 with permission). 


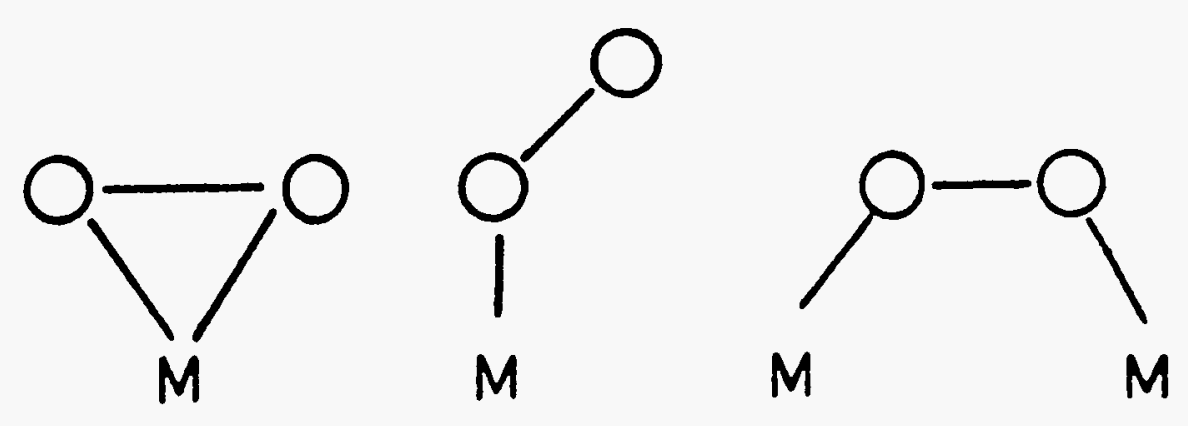




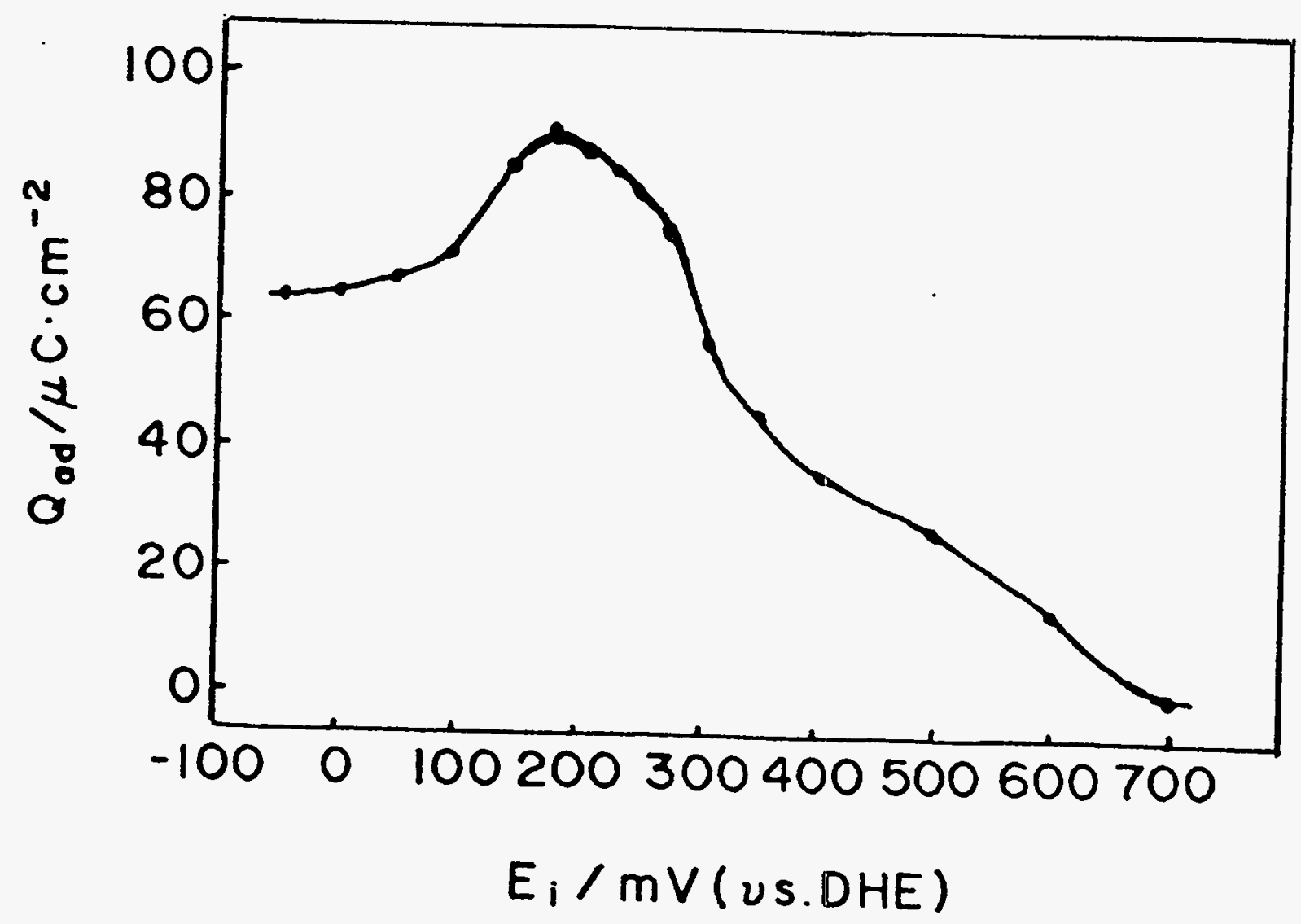



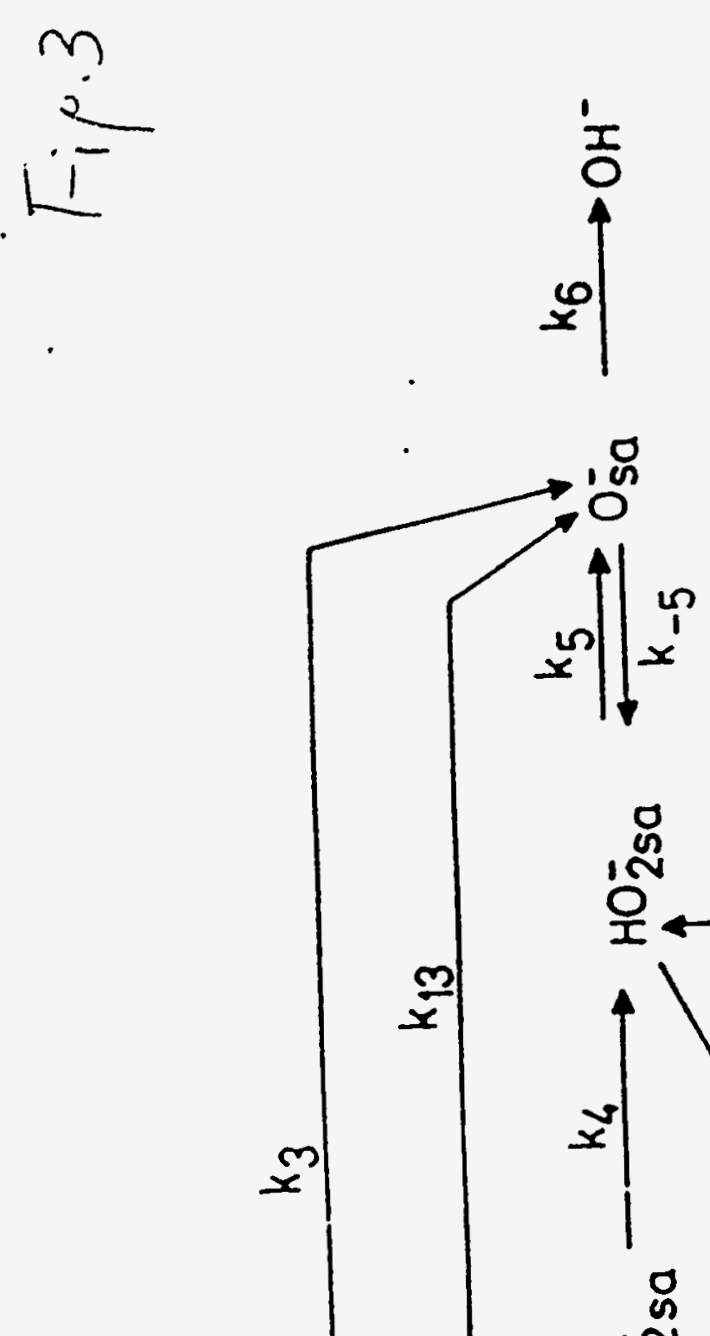


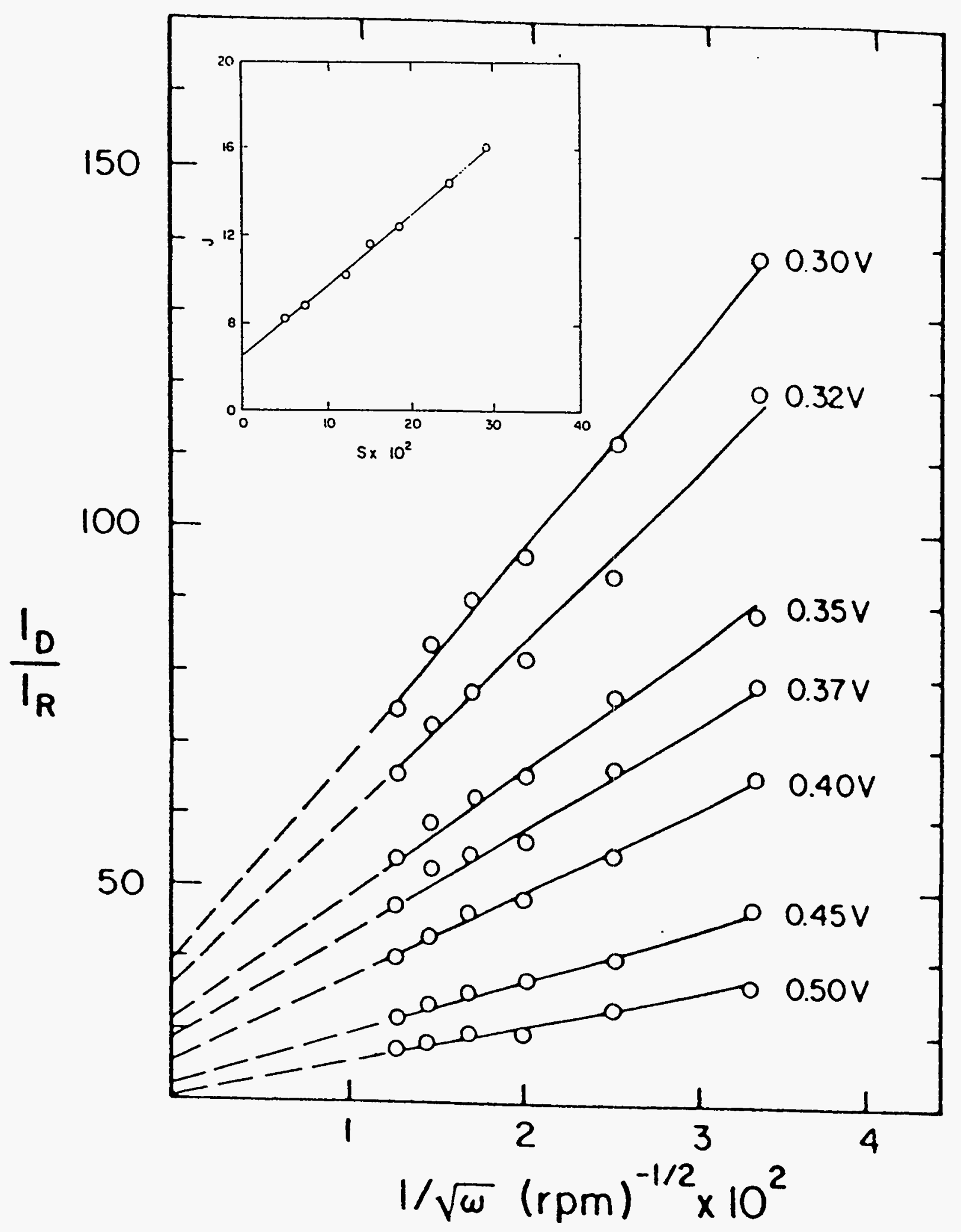




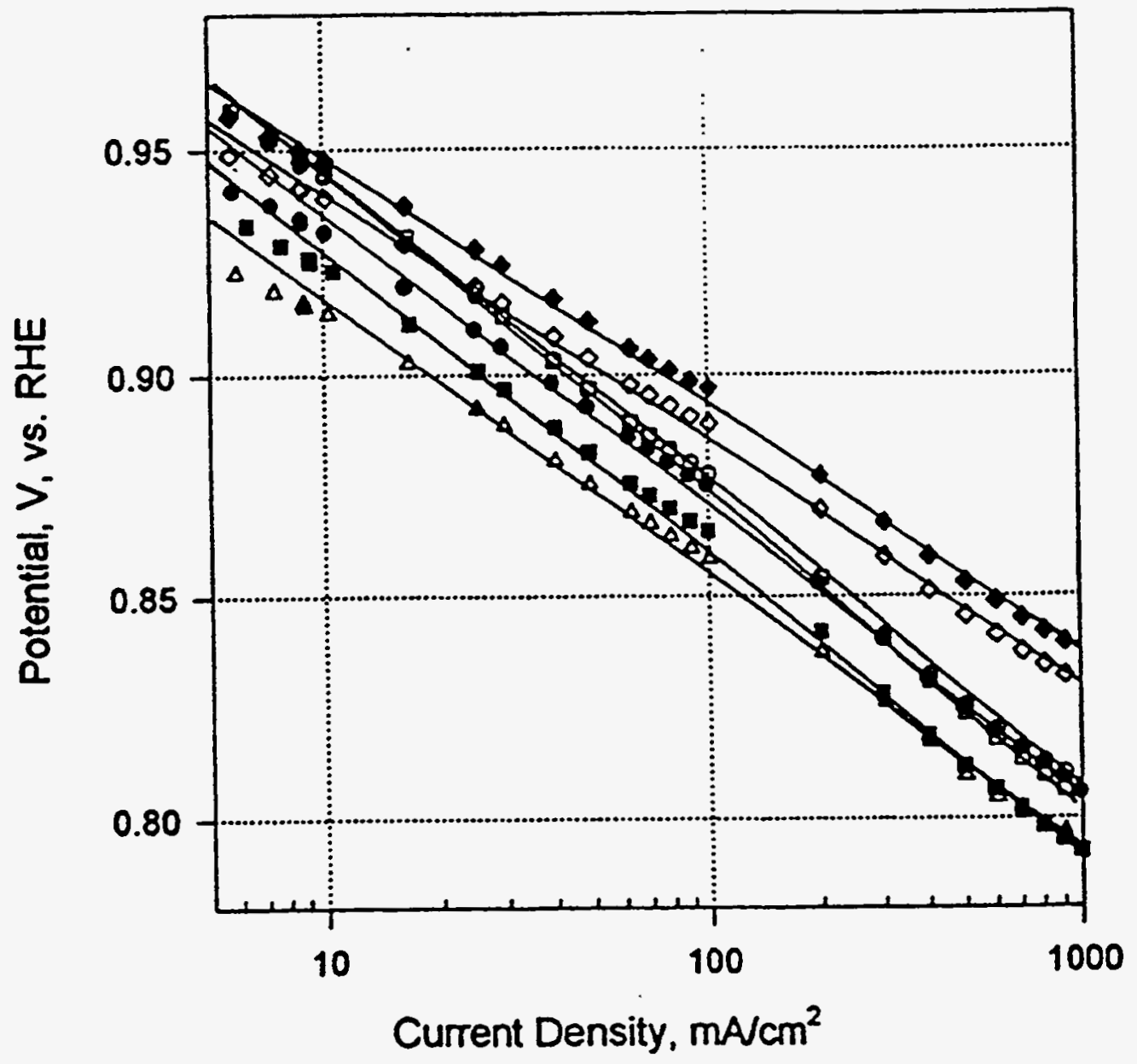




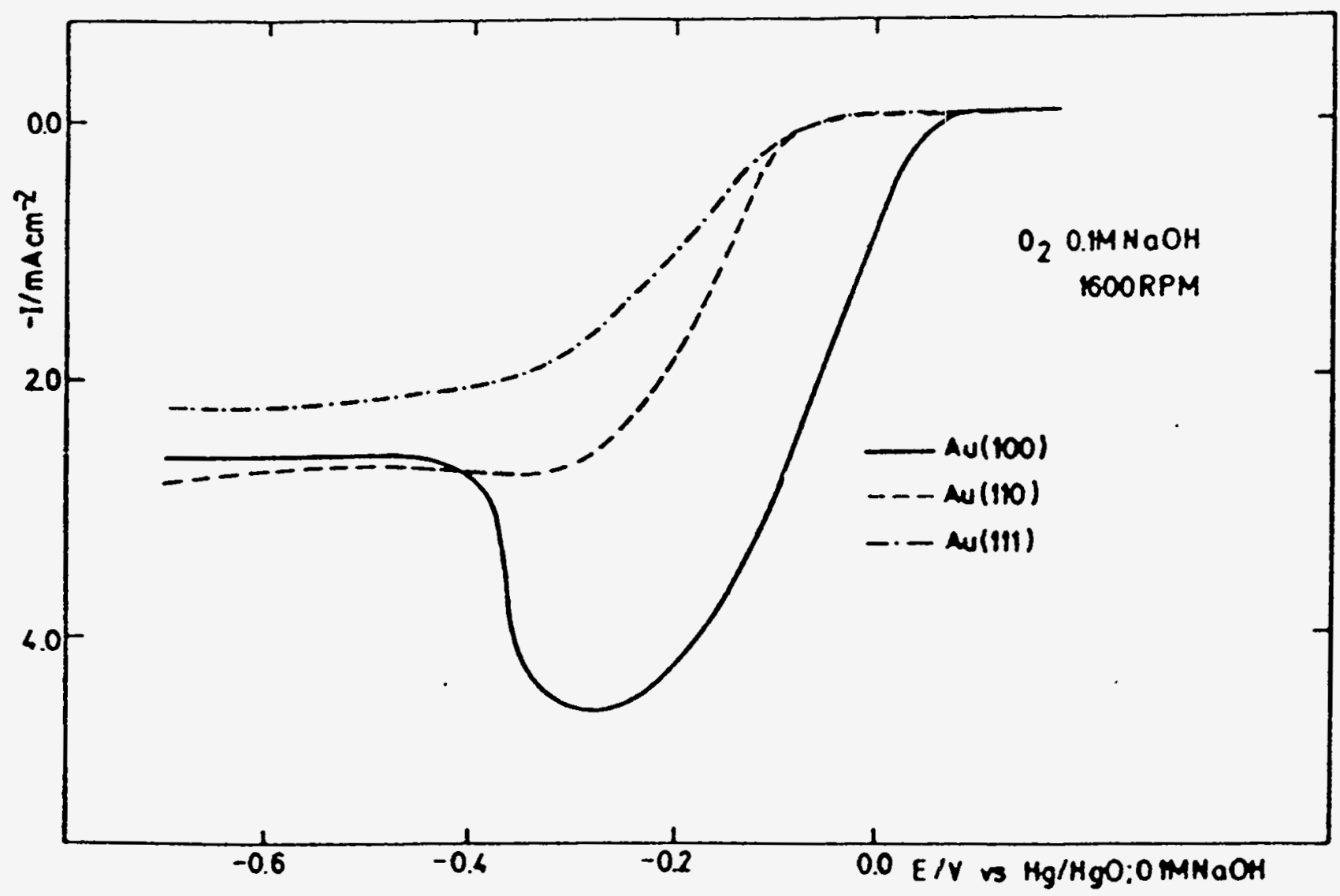


$F_{1} \cdot ?$

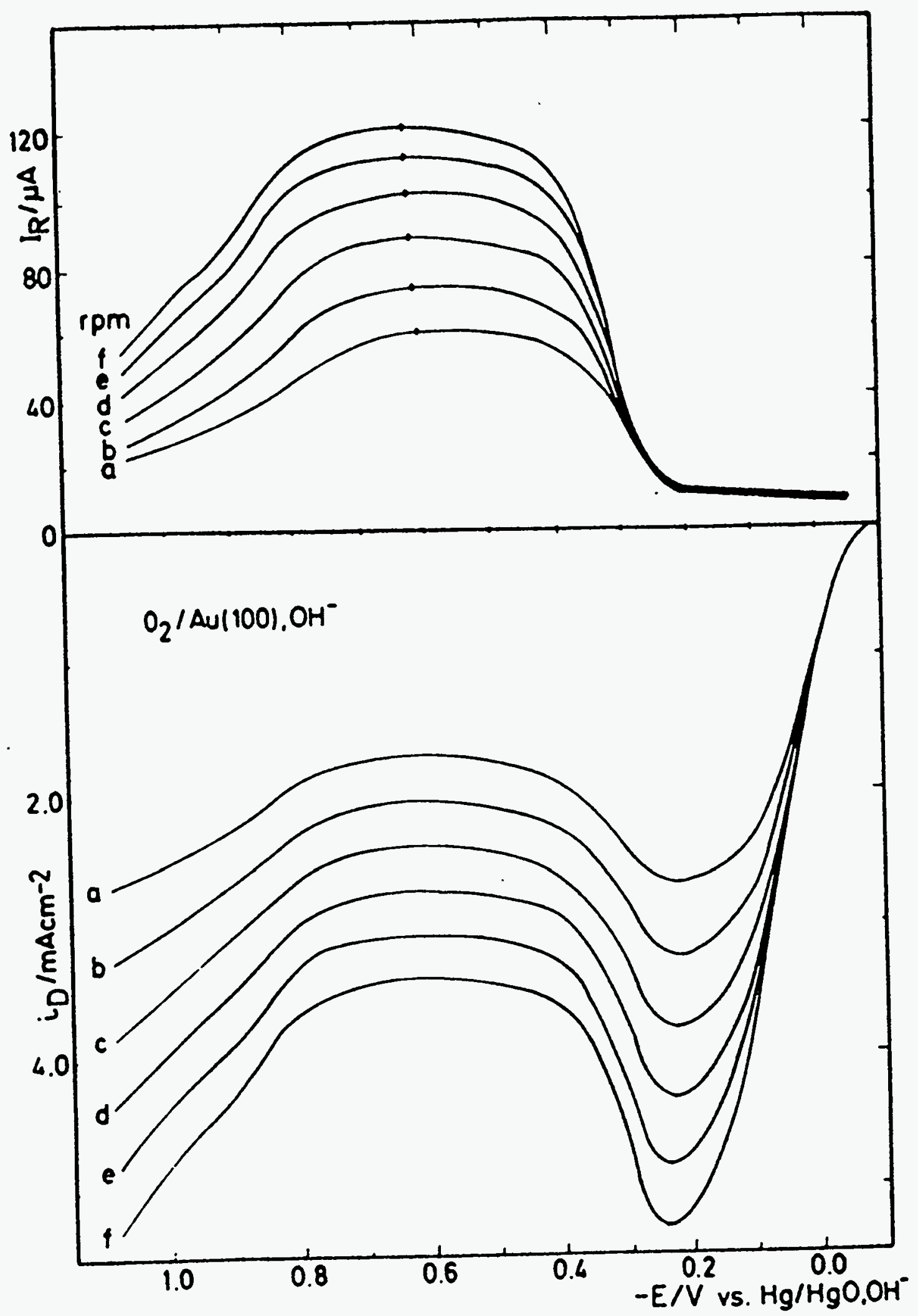


Fif 8

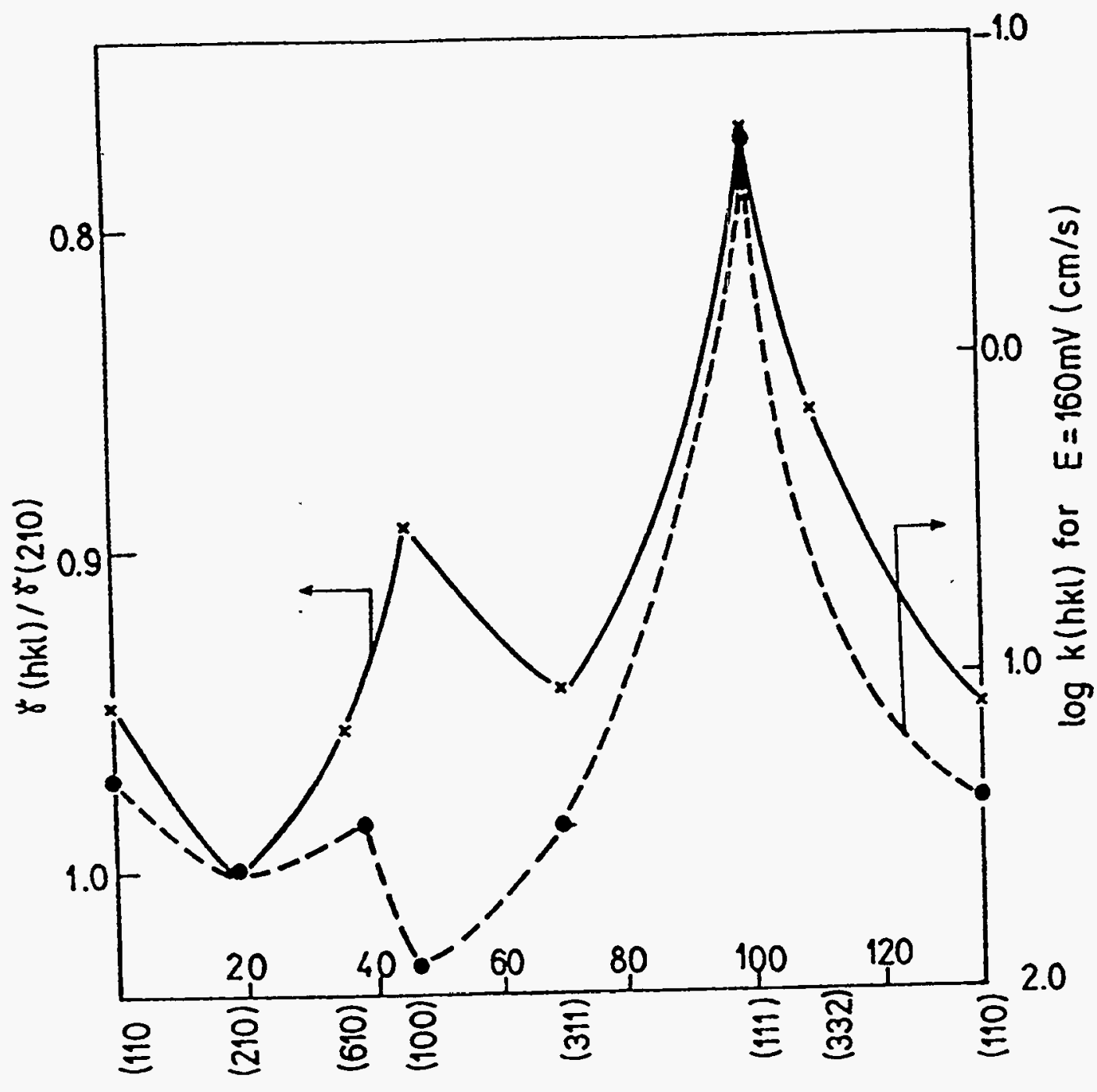


Fip.

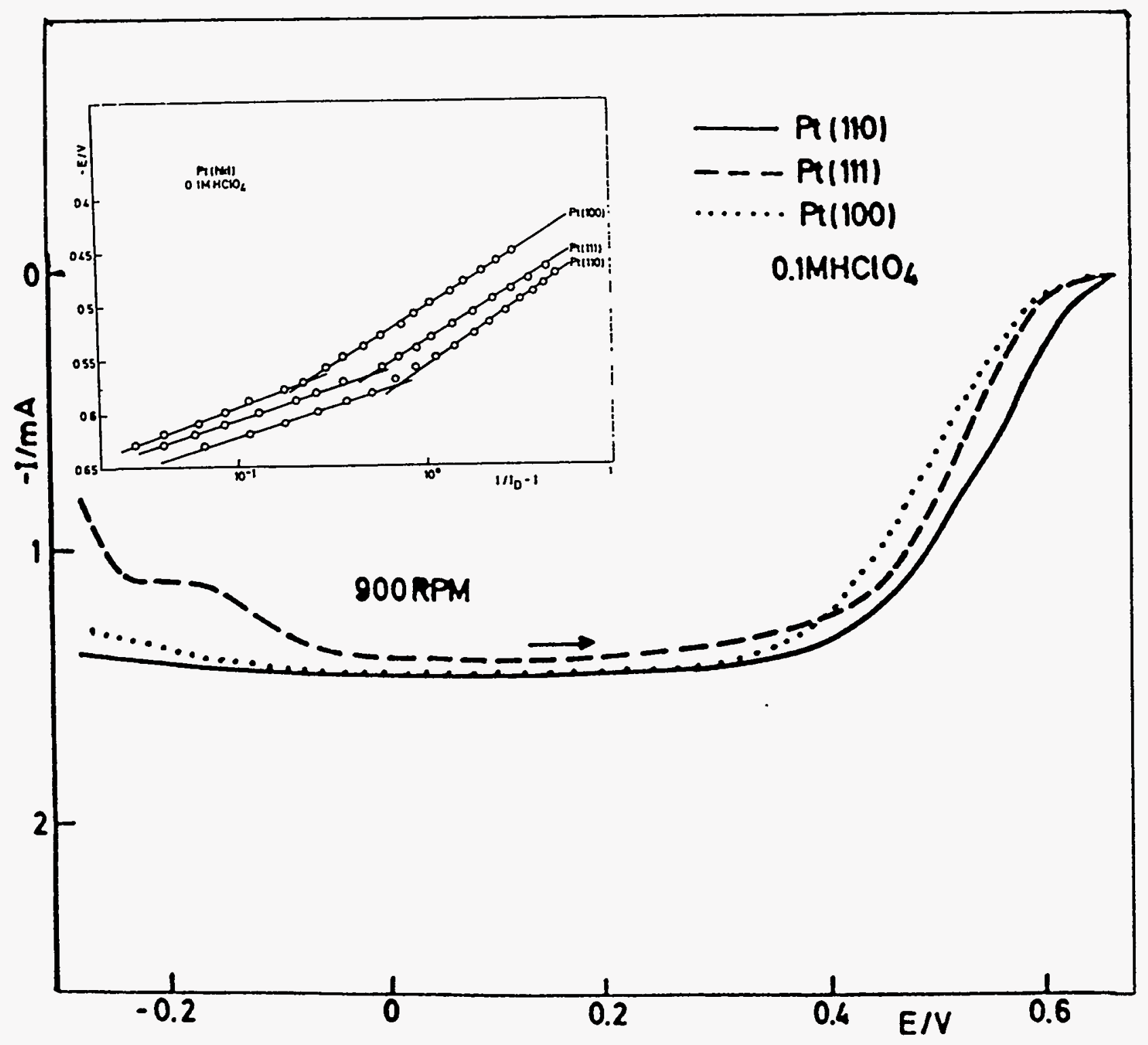


Fip. 10

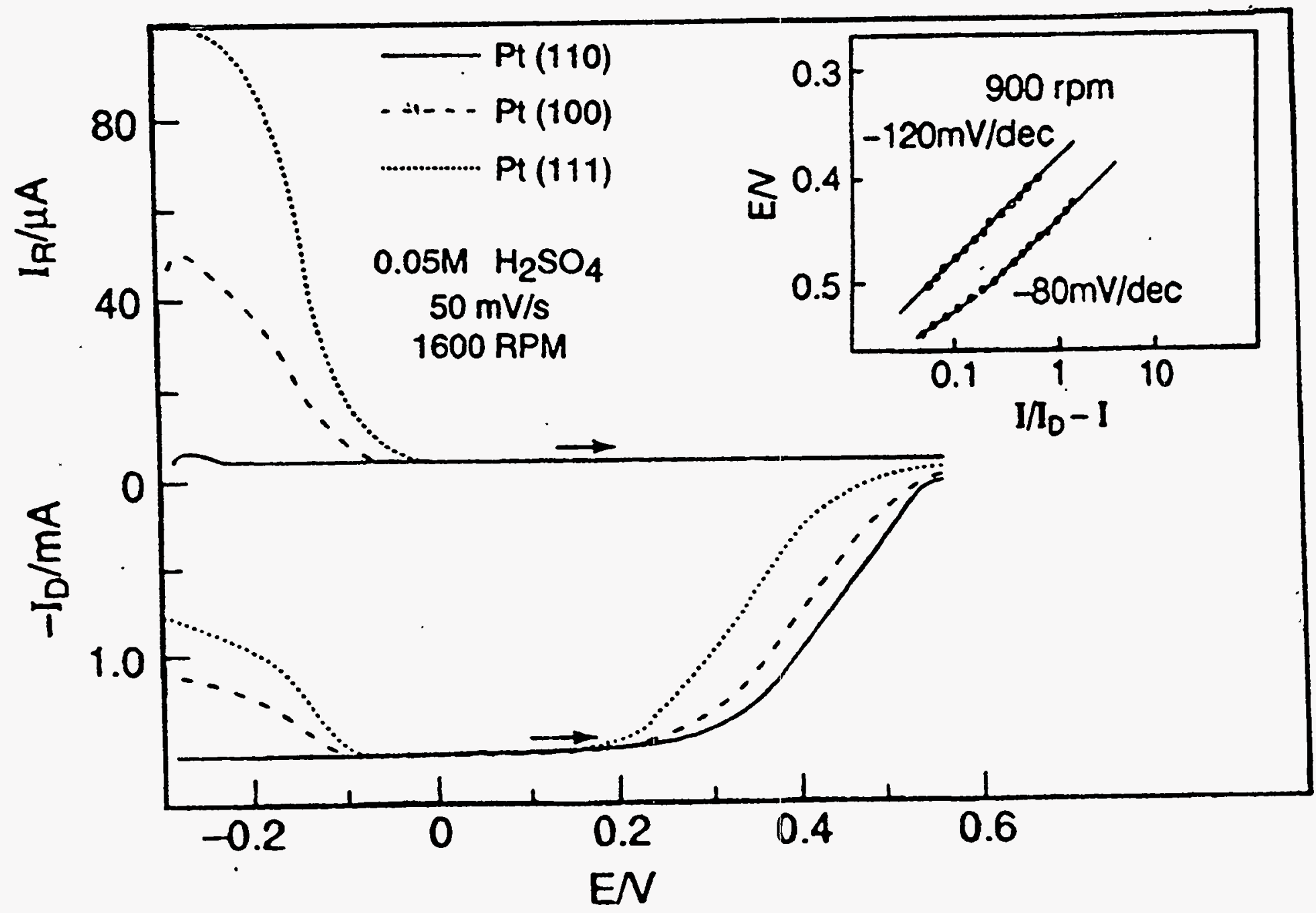




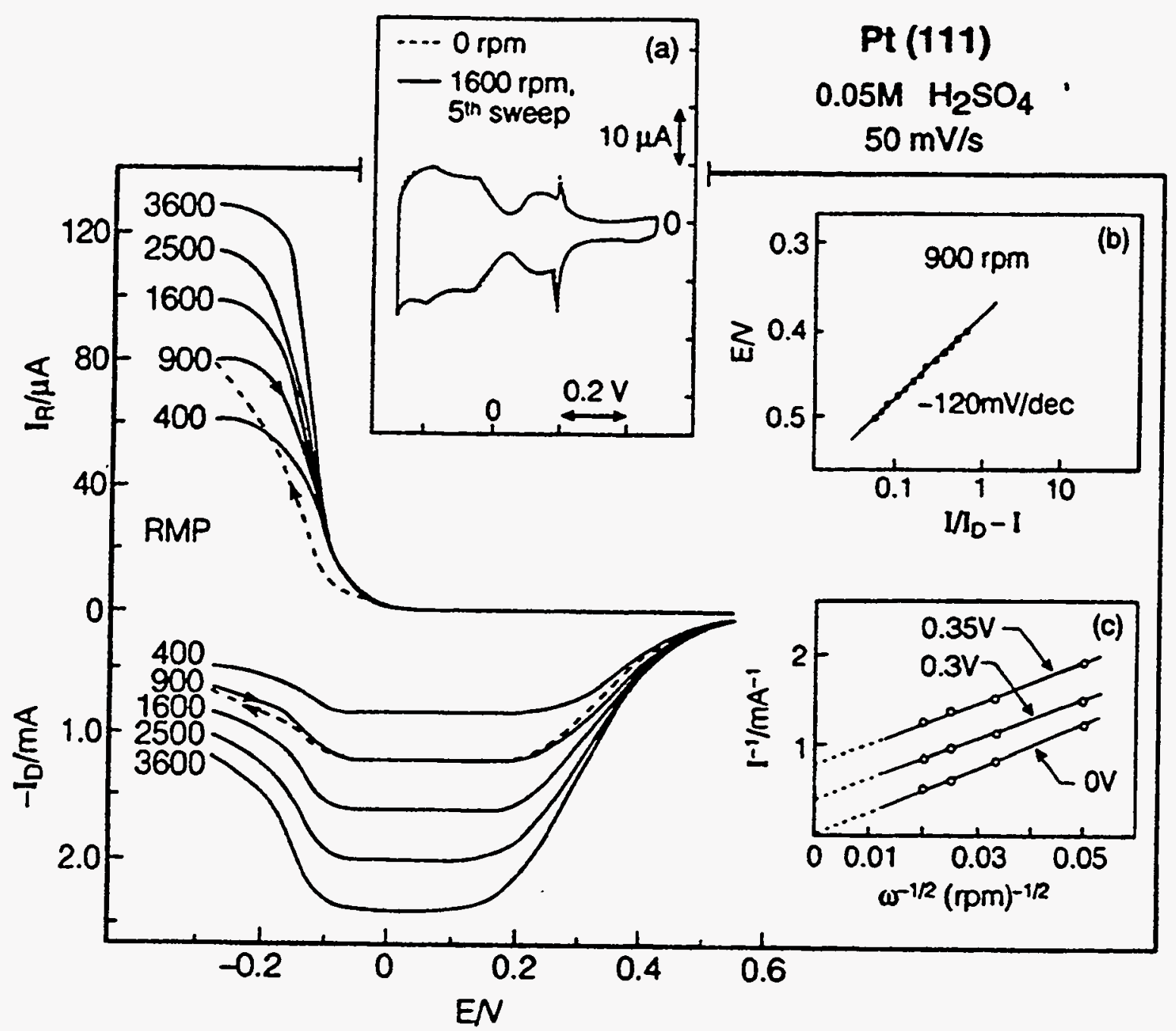


Fif. $=$

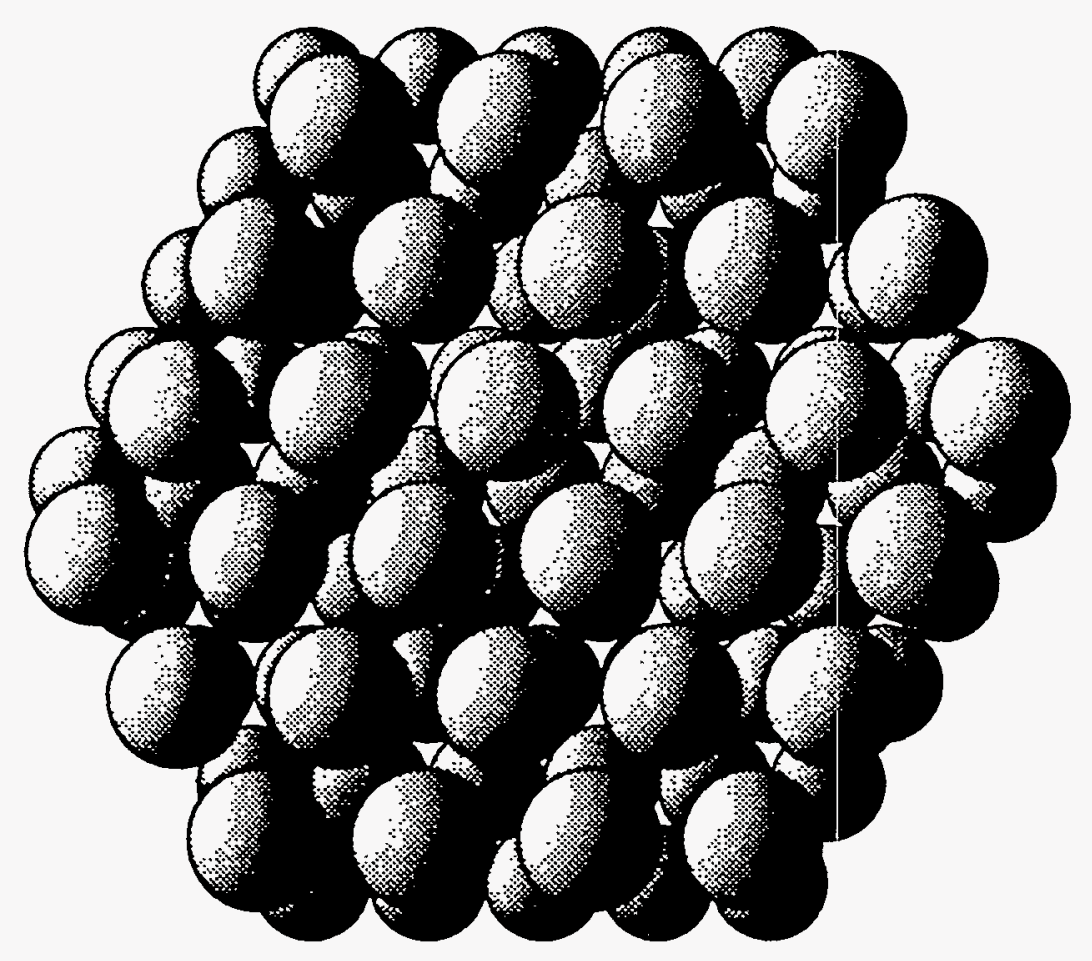




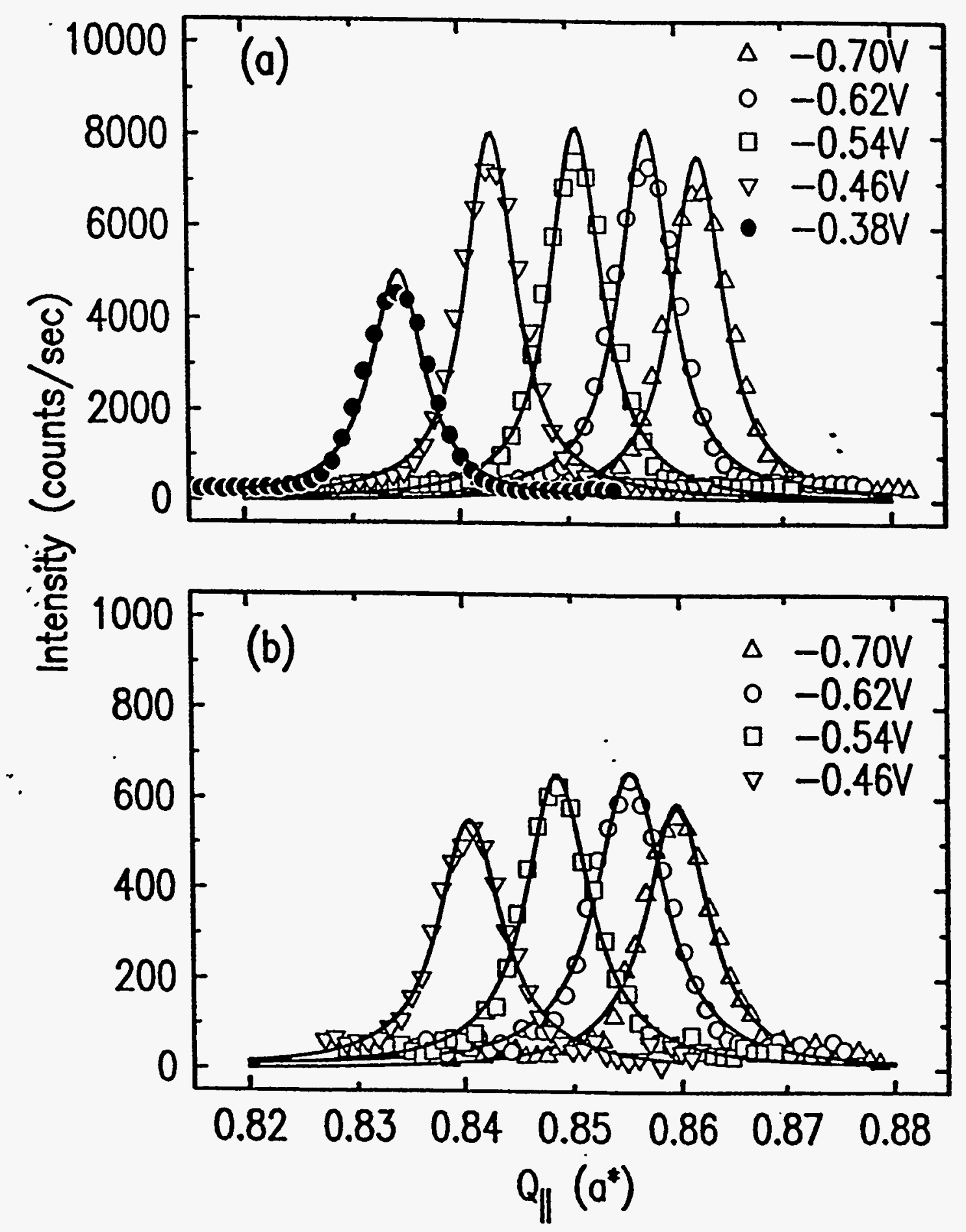


Fit

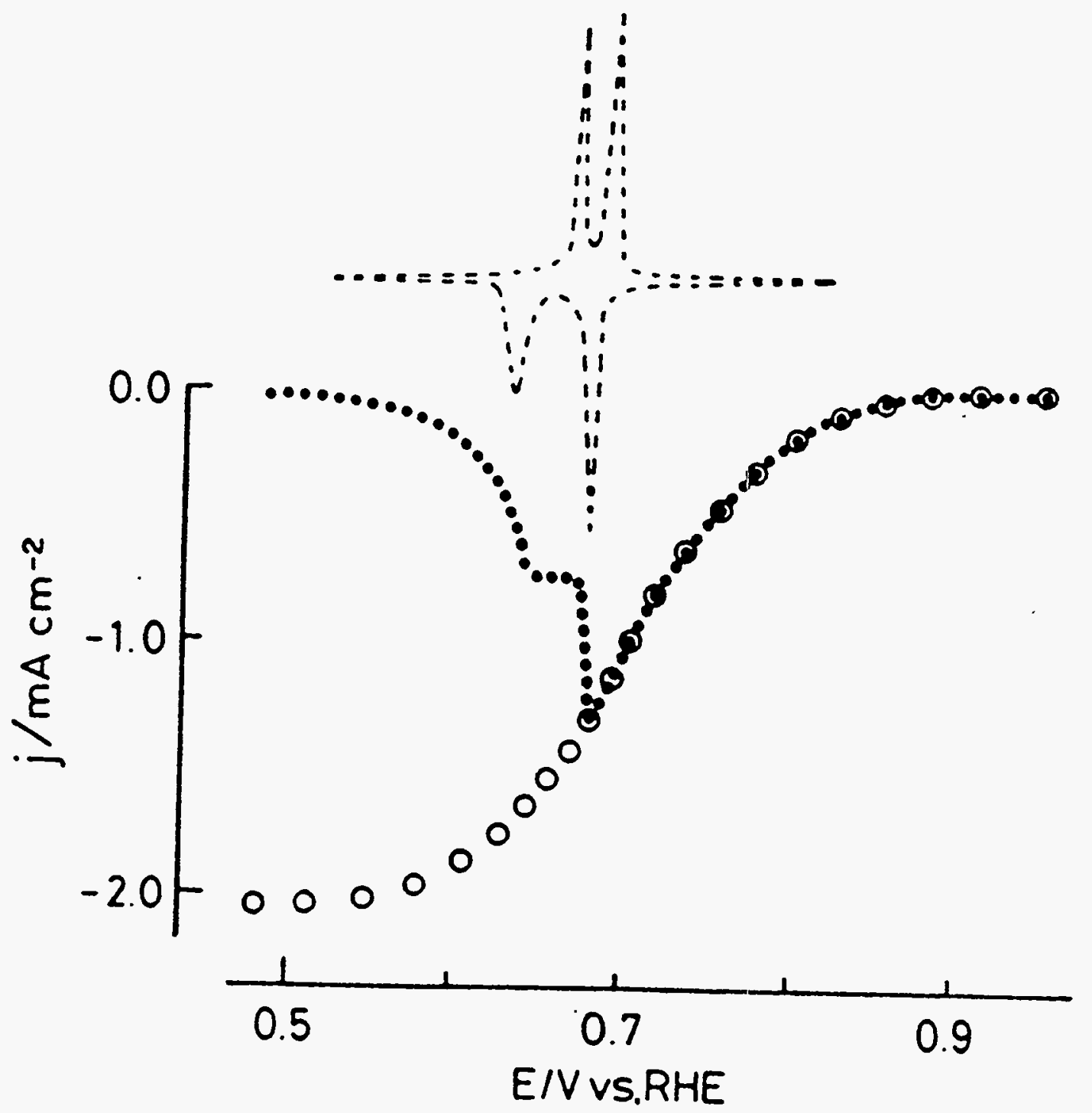


Fip. $1^{-}$

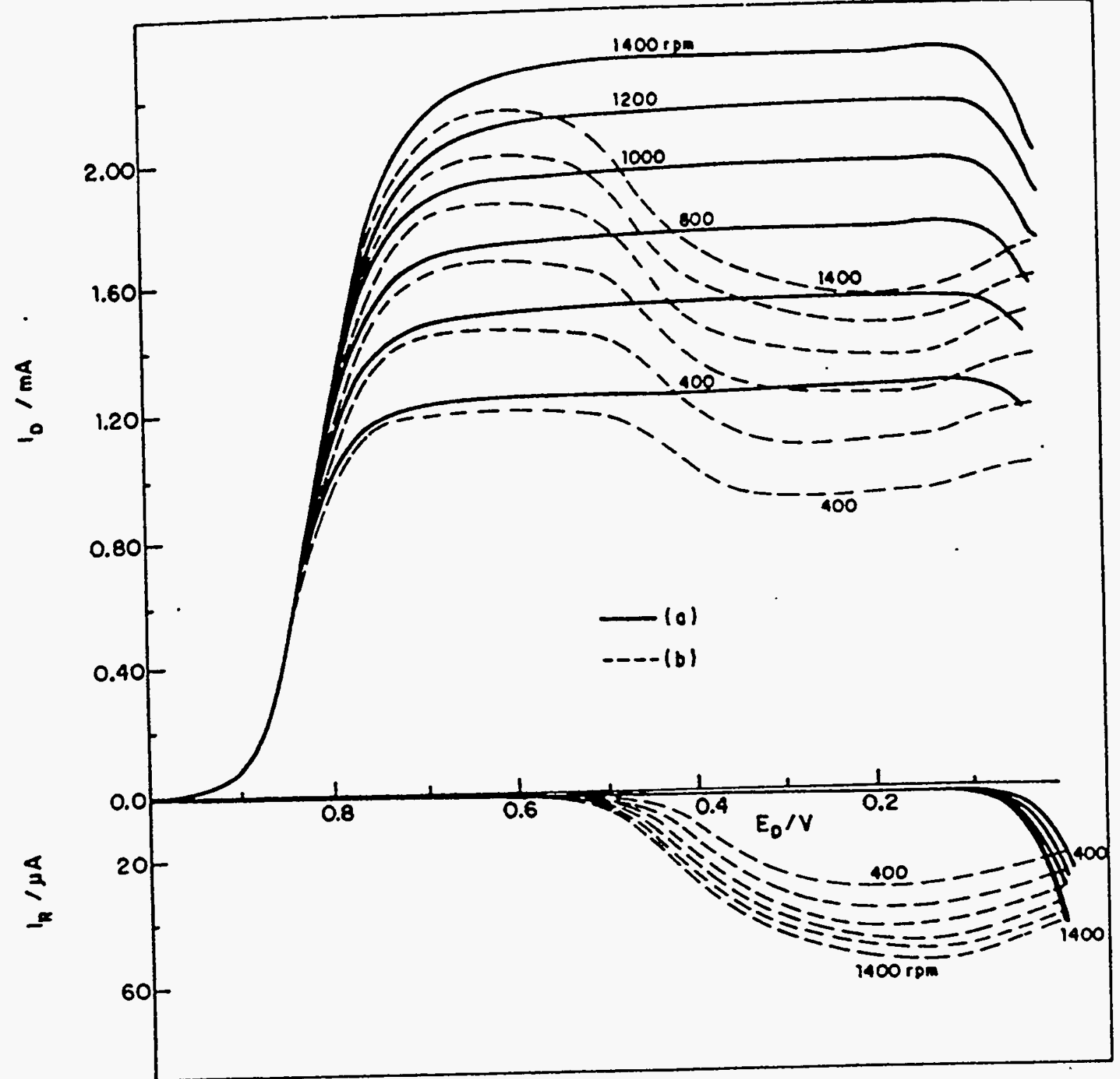


Fip lo

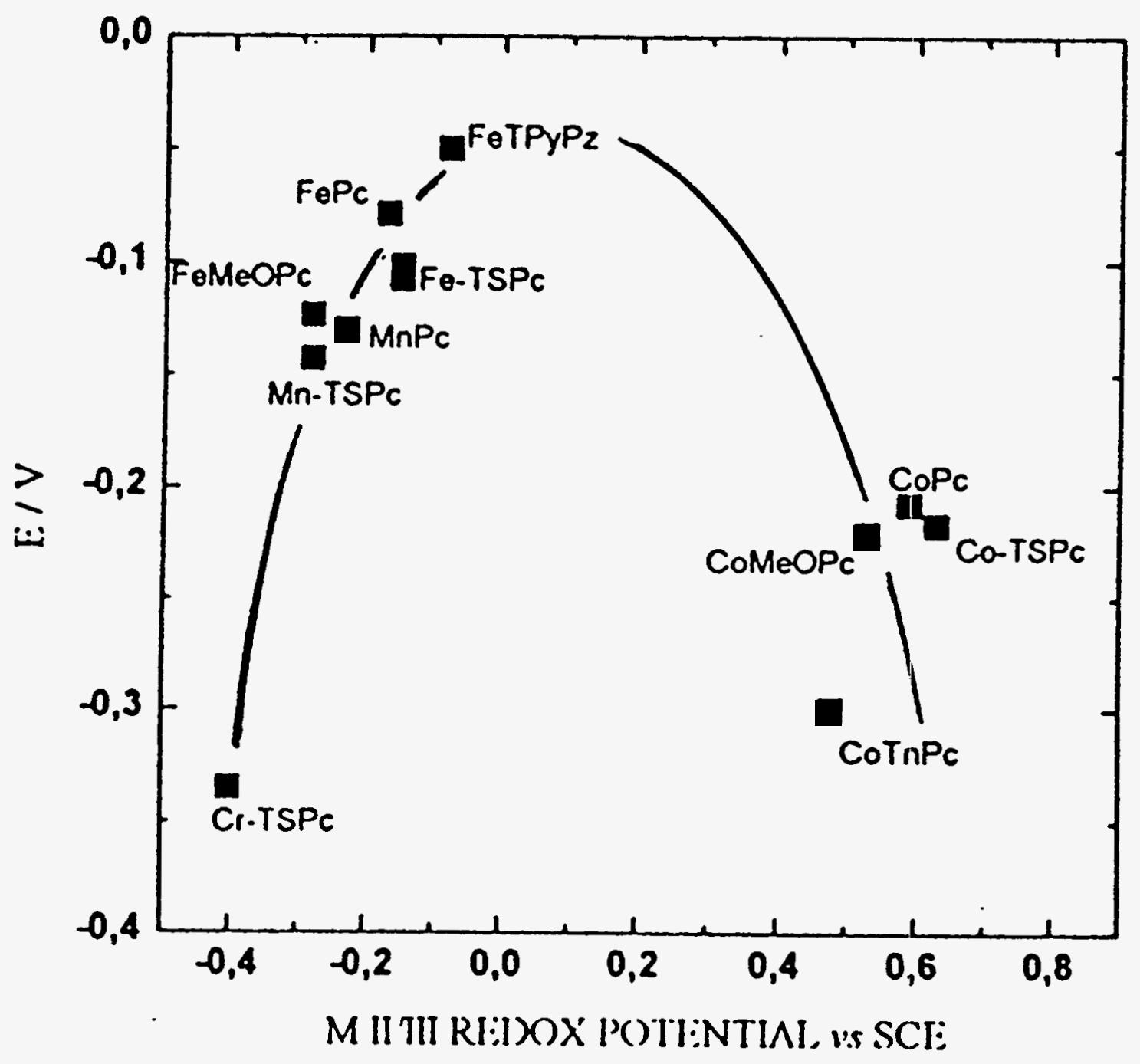




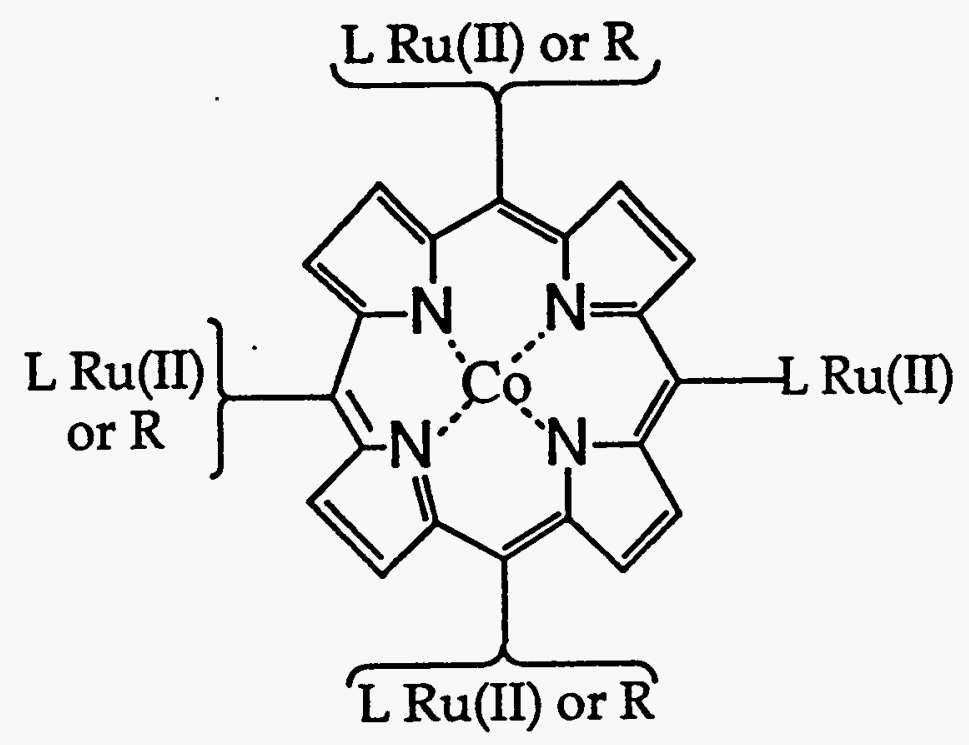

$$
\mathrm{Ru}(\mathrm{II})=\mathrm{Ru}\left(\mathrm{NH}_{3}\right)_{5}{ }^{2+}, \mathrm{Ru}(\text { edta })^{2-}
$$




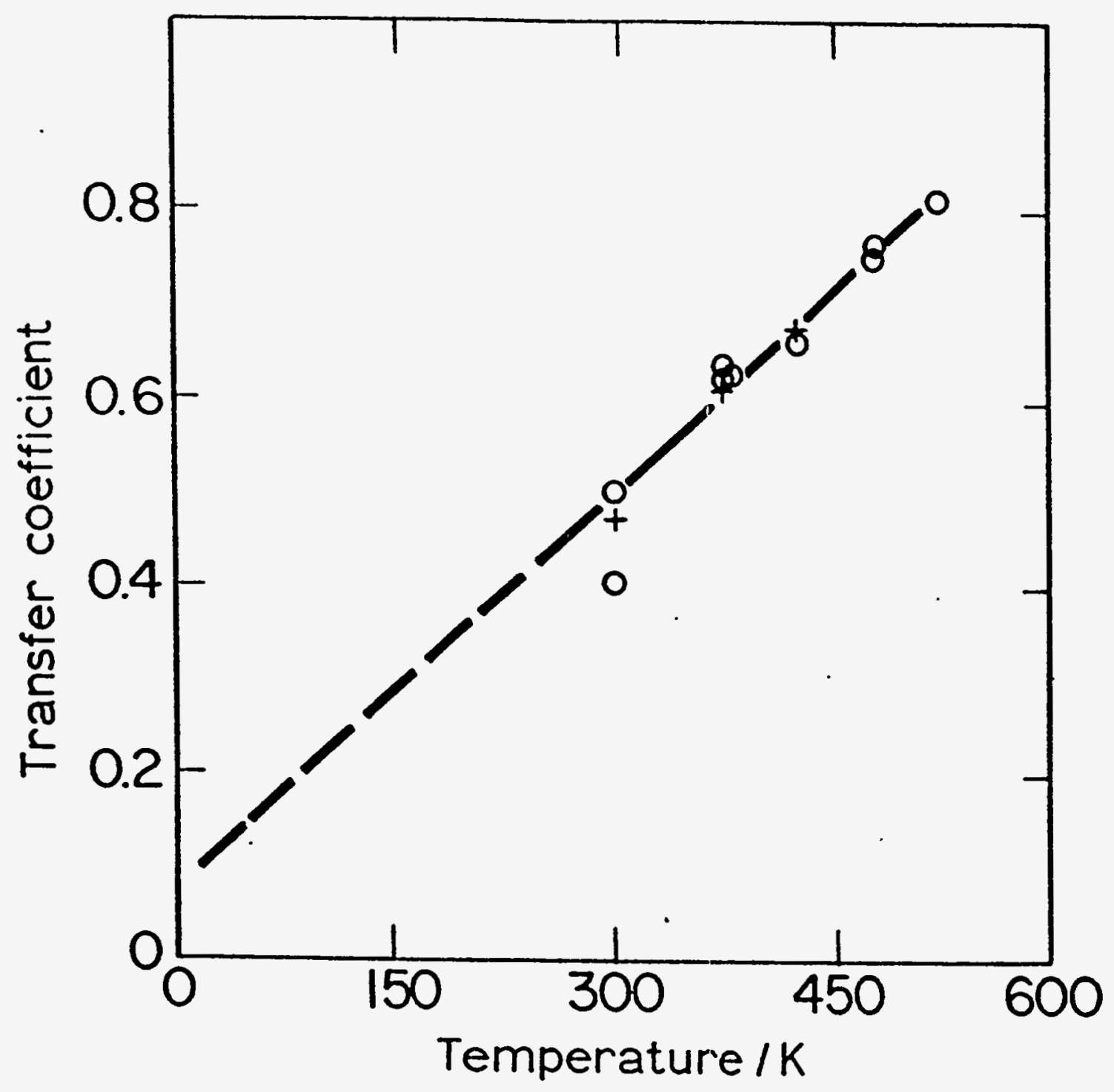

